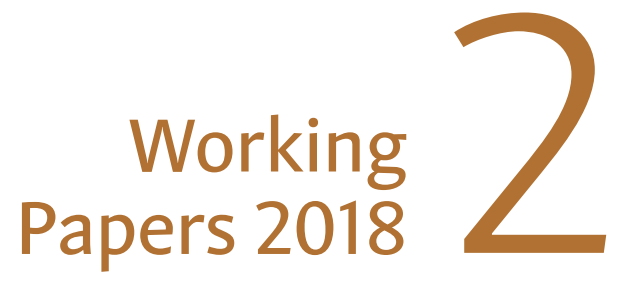

Are asset price data informative about news shocks? A DSGE perspective

Nikolay Iskrev

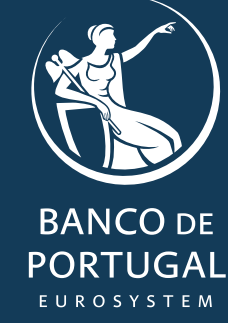





\section{Working \\ Papers 2018

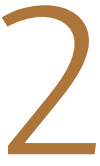

\section{Are asset price data informative about news shocks? A DSGE perspective}

Nikolay Iskrev

EUROSYSTEM 
Working Papers | Lisbon 2018 • Banco de Portugal Av. Almirante Reis, 71 | 1150-012 Lisboa • www.bportugal.pt • Edition Economics and Research Department • ISBN (online) 978-989-678-562-8 • ISSN (online) 2182-0422 


\title{
Are asset price data informative about news shocks? A DSGE perspective
}

\author{
Nikolay Iskrev \\ Banco de Portugal \\ UECE
}

19 March 2018

\begin{abstract}
Standard economic intuition suggests that asset prices are more sensitive to news than other economic aggregates. This has led many researchers to conclude that asset price data would be very useful for the estimation of business cycle models containing news shocks. This paper shows how to formally evaluate the information content of observed variables with respect to unobserved shocks in structural macroeconomic models. The proposed methodology is applied to two different real business cycle models with news shocks. The contribution of asset prices is found to be relatively small. The methodology is general and can be used to measure the informational importance of observables with respect to latent variables in DSGE models. Thus, it provides a framework for systematic treatment of such issues, which are usually discussed in an informal manner in the literature.
\end{abstract}

JEL: C32, C51, C52, E32

Keywords: DSGE models, News Shocks, Asset prices, Information, Identification.

Acknowledgements: I thank Stephanie Schmitt-Grohé, Ellen McGrattan, Marek Jarociński, Mark Watson, Michael Reiter, and participants in the 19th Central Bank Macroeconomic Modelling Workshop hosted by Central Bank of Armenia for useful conversations and comments. The views expressed in this publication are those of its author and do not necessarily reflect the views of Banco de Portugal or the Eurosystem.

E-mail: nikolay.iskrev@bportugal.pt 


\section{Introduction}

There is a general tendency in the study of business cycles towards estimating different types of models using a common set of macroeconomic aggregates. Perhaps the main reason for this is the desire to let models compete on the same ground and have results that are easy to compare with the rest of the literature. At the same time, as models evolve and new features are introduced, it sometimes appears necessary to expand the number and type of variables used to estimate them.

One of the important recent developments has been the idea that news shocks could be a significant driver of business cycles. The traditional explanation of business cycles is that they are caused by exogenous unanticipated changes in economic fundamentals. Following the work of Beaudry and Portier (2004, 2006), a lot of research has been devoted to the question whether anticipated changes in future fundamentals, or news shocks, could also be an important source of aggregate fluctuations.

News shocks are usually introduced in dynamic stochastic general equilibrium models (DSGE) models by adding anticipated components to innovations driving exogenous shock processes. From an econometric point of view, this raises the question of whether standard macroeconomic variables are sufficiently informative to estimate models with news, or different type of data are required. A common approach in many recent studies has been to estimate news-driven DSGE models using only variables that are also standard in the estimation of models without news. ${ }^{1}$ There are also some notable exceptions. For instance Davis (2007) uses term structure data, Hirose and Kurozumi (2012), Milani and Rajbhandari (2012), and Miyamoto and Nguyen (2015) use data on expectations, and Malkhozov and Tamoni (2015), Avdjiev (2016) and Görtz and Tsoukalas (2016) use asset price data. The authors of these papers contend that the variables they use are particularly informative with

1. In fact, it is a common practice to introduce news shocks to models that have previously been estimated without news, and estimate them using the same set of observables. 
respect to news shocks, and that without such variables it is difficult to identify and estimate accurately news shocks and their contribution to business cycle fluctuations.

No formal evidence is given to support these claims. For instance, the argument for using asset price data is based on the observation that asset prices are very responsive to changes in information, e.g. to news. Because of that, asset price data are perceived as being more informative about news shocks compared to other macroeconomic variables, which, due to various real and nominal rigidities, are less sensitive to news. Similar arguments can also be found in the structural VAR literature where asset prices, and in particular stock price data, often play a central role in the identification of news shocks. ${ }^{2}$

There are two potential problems with this line of reasoning when applied to the estimation of news-driven DSGE models. First, the identification of news derives from model-implied restrictions on the relationship between the unobserved shocks and the variables used to estimate the model. Thus, the information content of different variables depends on how news shocks are introduced and propagate in the particular model, and not on what the propagation mechanism is believed to be in reality. Second, if news are important for aggregate fluctuations, and not just for fluctuations in stock prices, then macroeconomic aggregates should be informative about news shocks. Since DSGE models impose many more identifying restrictions than SVARs, there could be enough information to separate news from other sources of fluctuations on the basis of standard macroeconomic variables.

This paper makes both a methodological and a substantive contribution. On the methodological side, it shows how to assess a DSGE model's implications regarding the contribution of information of observed variables with respect to unobserved shocks. Such issues are frequently discussed in a heuristic fashion in the DSGE literature. The main purpose here is to show how to approach

2. See, for instance Beaudry and Portier (2006) Barsky and Sims (2011), Kurmann and Otrok (2013), Barsky et al. (2014). 
them in a systematic manner. Intuitively, information can be interpreted as the reduction of uncertainty about an unknown quantity. This is made precise by using well-established measures of uncertainty, mutual information and information gains developed in information theory. The transfer of information is quantified by comparing different probability distributions, e.g. distributions of shocks conditional on nested sets of observables. The required distributions are completely characterized by the underlying structural model, and in the class of linearized Gaussian DSGE models, the required quantities are available in closed form. The application part of the paper evaluates the information content of asset price variables in two estimated real business cycle models featuring news shocks. The models are taken from Schmitt-Grohé and Uribe (2012) and Avdjiev (2016), and differ mainly in the number of fundamental shocks and in the way news shocks are introduced. The asset price variables considered are the value of the representative firm, which in the data is matched to stock price indices, and the risk-free real interest rate. For both models the results suggest relatively small contributions of asset prices with respect to news shocks. While including asset prices as observables increases the amount of information about some news shocks, their marginal contributions are comparable to the contributions of non-asset price variables, such as hours worked, total factor productivity or the relative price of investment. The only news shocks with respect to which asset prices, specifically the risk-free interest rate, are found to contribute more information than any other variable are the news about the stationary neutral productivity shock.

In terms of methodology, this paper is related to a large literature on measuring the relative importance of variables in scientific models. A common application of this type of analysis is to determine the relative importance of individual regressors in explaining the behavior of response variables (Kruskal (1987)). The use of information-theoretic measures in that context dates back at least to Theil (1987), who uses a decomposition of Gaussian mutual information to quantify the contribution of independent explanatory variables 
in multivariate regressions. ${ }^{3} \mathrm{~A}$ comprehensive treatment of the subject from an information theory perspective is given in Retzer et al. (2009), who characterize the importance of variables by the extent to which their use reduces uncertainty about predicting the response variable. Another important area of application is the study of causal relationships in the analysis of time series. Following the seminal work of Granger (1969), the notion of causality has been associated with the question of whether knowledge of past values of one time series helps improve the forecasts of another. While most of the early work on this topic focused on how to test for the existence and direction of causality, Geweke (1982, 1984) show how to quantify the strength of causal influence. Geweke's measures are based on the magnitude of the reduction of forecast uncertainty, measured by the mean square forecast errors of the predicted variable, due to using past values of the causal variable. In that sense, measuring Granger causality can be interpreted as quantifying the contribution of information by observed variables - past observations of the cause variable, with respect to unobserved ones - the future values of the predicted variable, conditional on a set of other observed variables - the past values of the predicted variable. ${ }^{4}$ This is precisely the meaning of conditional mutual information, and, as Barnett et al. (2009) show, when the join distribution of the variables is Gaussian, Geweke's measures of strength of causality are equivalent to the "transfer entropy" of Schreiber (2000), which is an information-theoretic measure of the transfer of information between two stochastic processes. ${ }^{5}$ Extensions to non-linear and non-Gaussian models involve replacing the forecast error variances with entropic measures of uncertainty (see Amblard and Michel (2011)). In a recent article Jarociński

3. See also Theil and Chung (1988) where the analysis is extended to systems of simultaneous equations, and Soofi (1992), who applies the same ideas to determine the relative importance of predictors in logit models.

4. In his Nobel prize acceptance lecture Granger defined causality as follows: (1) The cause occurs before the effect; (2) The cause contains information about the effect that is unique, and is in no other variable.

5. See also Pourahmadi and Soofi (2000) who use conditional mutual information to quantify the information worth of past observations for predicting future values of univariate time series. 
and Maćkowiak (2017) develop new analytical results for Granger causality in Bayesian vector autoregressions (VAR), and show how to use them for selecting the relevant variables to include in VAR models.

Instead of strength of causality, the purpose of the measures presented in this paper is to quantify the amount of information that realizations of observed variables contribute with respect to contemporaneous but unobserved realizations of structural shocks (or other latent variables). Since mathematically there is no difference between unobserved future realizations of observed variables and unobserved contemporaneous realizations of latent variables, the proposed measures of information gains are analogous, with minor modifications, to the Granger causality strength measures of Geweke $(1982,1984)$ in the case of linearized Gaussian DSGE models, and to non-linear Granger causality measures in the general case.

The paper is also related to a growing literature on the feasibility of recovering structural shocks using reduced form models. Building upon the work of Hansen and Sargent $(1980,1991)$ and Lippi and Reichlin $(1993,1994)$, most of the research on this topic has focused on the issue of invertibility (or fundamentalness) in structural vector autoregressions, i.e. whether shocks from general equilibrium models can be recovered from the residuals of VARs (see Alessi et al. (2011) and Giacomini (2013) for useful overviews of this literature). Conditions for invertibility are discussed in Fernandez-Villaverde et al. (2007), Ravenna (2007), Franchi and Vidotto (2013), Franchi and Paruolo (2015)), while Giannone and Reichlin (2006) and Forni and Gambetti (2014) discuss how to test for lack of invertibility of structural VARs. Invertibility issues that are specific to DSGE models with news shocks are discussed in Leeper et al. (2013) and Blanchard et al. (2013). More recently, Soccorsi (2016) and Sala et al. (2016) proposed measures of the degree of non-invertibility, which quantify the 
discrepancies between true shocks and shocks obtained using non-fundamental VARs. ${ }^{6}$

Similar to that literature, the analysis in the present paper can be used to determine if the shocks in a DSGE model can be recovered from a set of observed model variables. Furthermore, similar to Soccorsi (2016) and particularly Sala et al. (2016), a measure of the degree to which any individual shock, and more generally, any unobserved exogenous or endogenous model variable, can be recovered is provided. In particular, the proposed measures of information gains are defined with respect to a particular unobserved variable and show how much of the prior uncertainty about it is removed due to observing a set of model variables. An important difference with the invertibility literature is that the analysis here is based on the true data generating process characterized by a structural model, and not on approximations of it, such as a VAR. The proposed information gain measures are, in their general form, meaningful and useful when applied to non-linear DSGE models, while the invertibility conditions and measures in the existing literature are specific to linearized models. In the context of linearized DSGE models, the information gain measures could be interpreted as upper bounds on the amount of information about a shock (or the degree of information sufficiency in the terminology of Sala et al. (2016)) available in a VAR.

More importantly, while the existing research on invertibility is concerned with the usefulness of VAR-based tools for empirical validation of structural models, the purpose of the analysis presented here is to understand the properties of DSGE models in terms of how information transfers between observed and unobserved model variables. Therefore, identifying the main sources of information is of greater interest than what the total amount of information about a given shock is. To that end, I define and apply measures of conditional information gains that quantify the amount of additional

6. Simulation evidence that non-invertible VARs may in some cases produce good approximations of the true structural shocks are provided in Sims (2012) and Beaudry et al. (2015). 
information contributed by a variable or several variables, given the information contained in another set of observed variables. As the analysis of the models considered in the paper shows, the conclusions one draws may be very different depending on what the conditional variables are. For instance, asset prices are found to be unconditionally very informative with respect to wage markup news shocks in the model of Schmitt-Grohé and Uribe (2012), but conditional on observing other macro variables, the information gains are small. At the same time, asset prices may be conditionally quite informative about certain productivity news shocks even though the unconditional information gains are close to zero. These findings are a reflection of the fact that information contained in different variables is not necessarily independent and could be overlapping in some cases while complementary in others. A somewhat extreme example of this phenomenon is the finding that output growth is informationally completely redundant in the model of Schmitt-Grohé and Uribe (2012) and nearly redundant in the model of Avdjiev (2016). In general, information contained in different variables tends to be partially redundant with respect to some shocks and complementary with respect to others. A novel measure of pairwise information complementarity is introduced in the paper and used to determine the sign and assess the degree of complementarity among observed variables with respect to unobserved ones. In particular, the measure is used to clarify the nature of the interactions between asset prices and other macroeconomic variables in terms of information they convey with respect to news shocks.

Even though the focus of this paper is on evaluating the informational importance of observed variables with respect to unobserved shocks, an alternative interpretation of the issue is in terms of information about model parameters. Specifically, one could argue that asset prices are important for news shocks in the sense that observing such variables would significantly reduce the estimation uncertainty of parameters characterizing the distributions of these shocks. To evaluate the contribution of information by variables with respect to parameters, I compute efficiency gains by comparing 
the values of the Cramér-Rao lower bounds (hereafter denoted by CRLB)) conditional on different sets of observed variables. The same approach is used by Wei $(1978 \mathrm{a}, \mathrm{b})$ and Palm and Nijman (1984) to measure the effect of having missing observations due to temporal aggregation, and by Iskrev (2010) to assess the importance of different observables with respect to individual parameters in DSGE models. In a related study Canova et al. (2014) propose an alternative method for selecting the most informative subset of observables for singular models. Simulation-based evidence on the relative performance of Canova et al. (2014) approach and the CRLB-based predictions can be found in Iskrev and Ritto (2016).

The remainder of the paper is organized as follows. Section 2 gives an overview of the relevant information-theoretic concepts, and defines measures of information gains with respect to latent variables, and efficiency gains with respect to parameters. The proposed measures are then applied, in Section 3, to evaluate the information content of asset prices in two different DSGE models containing news shocks. Section 4 concludes.

\section{Measures of information and information gains}

A DSGE model completely characterizes the joint probability distribution of a $n_{\boldsymbol{y}}$ vector of observed endogenous variables $\boldsymbol{y}$, and a $n_{\boldsymbol{z}}$ vector of unobserved endogenous variables and exogenous shocks $\boldsymbol{z}$. Note that in practice the dimension of each of these vectors is a function of a sample size $T$. For notational simplicity I suppress the dependence on $T$ throughout this section unless it is necessary to make it explicit. The joint distribution function of $\boldsymbol{y}$ and $\boldsymbol{z}$ is parameterized in terms of a $n_{\boldsymbol{\theta}}$ vector of structural parameters $\boldsymbol{\theta}$, characterizing technology, preferences, and the properties of the exogenous variables. Both $\boldsymbol{\theta}$ and $\boldsymbol{z}$ are typically unknown and unobserved, and the only source of empirical information about them are the measurements of $\boldsymbol{y}$. The purpose of this section is to show how to quantify the amount of information contained in a sample of data, and how to evaluate the contributions of individual observed variables. 
One way to approach these questions would be to adopt a Bayesian perspective and treat $\boldsymbol{z}$ as part of the parameter vector to be estimated. Then, the amount of information provided by a sample would be with respect to $(\boldsymbol{\theta}, \boldsymbol{z})$ jointly. While conceptually feasible, this approach would be very challenging in practice in the present context, given the large dimension of $\boldsymbol{z}$ and the complicated form of the conditional distribution of $(\boldsymbol{\theta}, \boldsymbol{z})$ given $\boldsymbol{y}$. Therefore, in most of this section I treat $\boldsymbol{\theta}$ as known and measure sample information and information gains about $\boldsymbol{z}$ conditional on $\boldsymbol{\theta}$. At the end of the section I discuss the issue of measuring sample information about $\boldsymbol{\theta}$.

\subsection{Information about latent variables}

A well-established measure of information about random variables is the information-theoretic entropy introduced by Shannon (1948). Entropy is a measure of the uncertainty associated with a random variable, and the amount of information about that variable is measured as the reduction in uncertainty, i.e. entropy, relative to some base distribution. Specifically, let $f(\boldsymbol{z})$ be the probability density function of $\boldsymbol{z}$. For notational simplicity throughout this subsection I suppress the dependence on $\boldsymbol{\theta}$. The entropy $\mathrm{H}(\boldsymbol{z})$ of $f(\boldsymbol{z})$ is defined as

$$
\mathrm{H}(\boldsymbol{z}):=-\int f(\boldsymbol{z}) \ln (f(\boldsymbol{z})) d \boldsymbol{z}=-\mathrm{E} \ln f(\boldsymbol{z}) .
$$

Similarly, if $f(\boldsymbol{y}, \boldsymbol{z})$ is the joint probability density function of $\boldsymbol{y}$ and $\boldsymbol{z}$, the joint entropy $\mathrm{H}(\boldsymbol{y}, \boldsymbol{z})$ of $f(\boldsymbol{y}, \boldsymbol{z})$ is defined as

$$
\mathrm{H}(\boldsymbol{y}, \boldsymbol{z}):=-\int f(\boldsymbol{y}, \boldsymbol{z}) \ln (f(\boldsymbol{y}, \boldsymbol{z})) d \boldsymbol{y} d \boldsymbol{z}=-\mathrm{E} \ln f(\boldsymbol{y}, \boldsymbol{z})
$$

The difference between joint and marginal entropies

$$
\mathrm{H}(\boldsymbol{z} \mid \boldsymbol{y})=\mathrm{H}(\boldsymbol{y}, \boldsymbol{z})-\mathrm{H}(\boldsymbol{y})
$$

defines the conditional entropy of $\boldsymbol{z}$ given $\boldsymbol{y}$. It measures the amount of uncertainty about $\boldsymbol{z}$ that remains once $\boldsymbol{y}$ is observed. Note that $\mathrm{H}(\boldsymbol{z} \mid \boldsymbol{y})$ can 
be computed as in (2.1) using the conditional density $f(\boldsymbol{z} \mid \boldsymbol{y})$ of $\boldsymbol{z}$ given $\boldsymbol{y}$. It can be shown (see for instance Granger and Lin (1994)) that $\mathrm{H}(\boldsymbol{z}) \geq \mathrm{H}(\boldsymbol{z} \mid \boldsymbol{y})$ with equality if and only if $f(\boldsymbol{y}, \boldsymbol{z})=f(\boldsymbol{y}) f(\boldsymbol{z})$. Hence, unless $\boldsymbol{y}$ and $\boldsymbol{z}$ are independent, observing $\boldsymbol{y}$ provides information about $\boldsymbol{z}$. The amount of uncertainty about $\boldsymbol{z}$ that is removed by observing $\boldsymbol{y}$ is known as the mutual information of $\boldsymbol{y}$ and $\boldsymbol{z}$, i.e. ${ }^{7}$

$$
\mathrm{I}(\boldsymbol{y}, \boldsymbol{z})=\mathrm{H}(\boldsymbol{z})-\mathrm{H}(\boldsymbol{z} \mid \boldsymbol{y}) .
$$

$\mathrm{I}(\boldsymbol{y}, \boldsymbol{z})$ is a measure of information in the sense that it quantifies the expected reduction in uncertainty about one of the variables due to observing the other one. From $\mathrm{H}(\boldsymbol{z}) \geq \mathrm{H}(\boldsymbol{z} \mid \boldsymbol{y})$ it follows that mutual information is positive unless $\boldsymbol{y}$ and $\boldsymbol{z}$ are independent in which case it is zero. On the other hand, if the variables are perfectly dependent i.e. there exists a one-to-one function $g$ such that $\boldsymbol{z}=g(\boldsymbol{y})$, observing $\boldsymbol{y}$ is equivalent to observing $\boldsymbol{z}$. In that case $\mathrm{I}(\boldsymbol{y}, \boldsymbol{z})=\infty$ (see Granger and Lin (1994, Theorem 2)). It is common in practice to normalize the measure to be in the interval $[0,1]$. For instance, Joe (1989) proposed the following transformation

$$
\mathrm{I}^{*}(\boldsymbol{y}, \boldsymbol{z})=1-\exp (-2 \mathrm{I}(\boldsymbol{y}, \boldsymbol{z}))
$$

as a generalized measure of dependence between two or more random variables. The same transformation is used in Granger and Lin (1994) as a criterion for determining the number of significant lags in nonlinear time series models. The reason why the particular form in (2.5) is chosen is that, for a bivariate Gaussian distribution, $\mathrm{I}^{*}(\boldsymbol{y}, \boldsymbol{z})=\rho^{2}$, where $\rho$ is the linear correlation coefficient between $\boldsymbol{y}$ and $\boldsymbol{z}$. Furthermore, when $\boldsymbol{y}$ and $\boldsymbol{z}$ are jointly Gaussian, the transformation

7. Mutual information is defined as $\mathrm{I}(\boldsymbol{y}, \boldsymbol{z}):=\int f(\boldsymbol{y}, \boldsymbol{z}) \ln \frac{f(\boldsymbol{y}, \boldsymbol{z})}{f(\boldsymbol{y}) f(\boldsymbol{z})} d \boldsymbol{y} d \boldsymbol{z}$ and measures the distance between the joint distribution of $\boldsymbol{y}$ and $\boldsymbol{z}$ and the distribution when the variables are independent. See Cover and Thomas (2006) for more details on the properties of entropy and mutual information. 
in (2.5) results in the following expression ${ }^{8}$

$$
\mathrm{I}^{*}(\boldsymbol{y}, \boldsymbol{z})=\frac{\left|\boldsymbol{\Sigma}_{\boldsymbol{z}}\right|-\left|\boldsymbol{\Sigma}_{\boldsymbol{z} \mid \boldsymbol{y}}\right|}{\left|\boldsymbol{\Sigma}_{\boldsymbol{z}}\right|}
$$

where $\boldsymbol{\Sigma}_{\boldsymbol{z}}$ is the covariance matrix of the marginal probability density of $\boldsymbol{z}$, and $\boldsymbol{\Sigma}_{\boldsymbol{z} \mid \boldsymbol{y}}$ is the covariance matrix of the conditional probability density of $\boldsymbol{z}$ given $\boldsymbol{y}$. Hence, for Gaussian distributions, $I^{*}(\boldsymbol{y}, \boldsymbol{z})$ measures the reduction in the generalized variance (Wilks (1932)) of vector $\boldsymbol{z}$ due to observing vector $\boldsymbol{y}$, as a fraction of the unconditional generalized variance of $\boldsymbol{z}$. However, as Peña and Rodríguez (2003) and others have noted, the generalized variance is not a dimensionless measure of the uncertainty of a (Gaussian) random vector. For instance, if $\boldsymbol{\Sigma}_{\boldsymbol{z}}$ is a $n_{\boldsymbol{z}} \times n_{\boldsymbol{z}}$ diagonal matrix with $\sigma^{2}<1$ on the diagonal, $\left|\boldsymbol{\Sigma}_{\boldsymbol{z}}\right|=\sigma^{2 n_{\boldsymbol{z}}}$, implying exponential decline of uncertainty as the dimension of $\boldsymbol{z}$ grows. A dimensionless measure of variability proposed in Peña and Linde (2007) is the effective variance $\mathrm{V}_{e}(\boldsymbol{z})$, defined as

$$
\mathrm{V}_{e}(\boldsymbol{z}):=\left|\boldsymbol{\Sigma}_{\boldsymbol{z}}\right|^{1 / n_{\boldsymbol{z}}}
$$

When the elements of $\boldsymbol{z}$ are independent, i.e. $\boldsymbol{\Sigma}_{\boldsymbol{z}}$ is diagonal, the effective variance is equal to the geometric average of the variances of the elements of $\boldsymbol{z}$. In the general case, $\mathrm{V}_{e}(\boldsymbol{x})$ is equal to the geometric average of the eigenvalues of $\boldsymbol{\Sigma}$. Adopting the effective variance as a scalar measure of the uncertainty associated with Gaussian distributions yields the following measure of the information gained about $\boldsymbol{z}$ from observing $\boldsymbol{y}$ :

$$
\mathrm{IG}_{\boldsymbol{z}}(\boldsymbol{y})=\left(\frac{\left|\boldsymbol{\Sigma}_{\boldsymbol{z}}\right|^{1 / n_{\boldsymbol{z}}}-\left|\boldsymbol{\Sigma}_{\boldsymbol{z} \mid \boldsymbol{y}}\right|^{1 / n_{\boldsymbol{z}}}}{\left|\boldsymbol{\Sigma}_{\boldsymbol{z}}\right|^{1 / n_{\boldsymbol{z}}}}\right) 100 .
$$

The interpretation of $\operatorname{IG}_{\boldsymbol{z}}(\boldsymbol{y})$ is the following: it measures the reduction in uncertainty about vector $\boldsymbol{z}$ due to observing vector $\boldsymbol{y}$, as a percent of the unconditional (prior) uncertainty about $\boldsymbol{z}$.

8. This follows from the result that the entropy of a $n_{\boldsymbol{v}}$-dimensional Gaussian variable $\boldsymbol{v} \sim \mathbb{N}\left(\boldsymbol{\mu}_{\boldsymbol{v}}, \boldsymbol{\Sigma}_{\boldsymbol{v}}\right)$ is $\mathrm{H}(\boldsymbol{v})=0.5\left(\ln (2 \pi e)^{n_{v}}+\ln \left|\boldsymbol{\Sigma}_{\boldsymbol{v}}\right|\right)$. Therefore, the mutual information of $\boldsymbol{y}$ and $\boldsymbol{z}$ is $\mathrm{I}(\boldsymbol{y}, \boldsymbol{z})=\mathrm{H}(\boldsymbol{z})-\mathrm{H}(\boldsymbol{z} \mid \boldsymbol{y})=.5 \ln \left(\frac{\left|\boldsymbol{\Sigma}_{\boldsymbol{z}}\right|}{\left|\boldsymbol{\Sigma}_{\boldsymbol{z} \mid \boldsymbol{y}}\right|}\right)$. 
The measure in (2.8) can be generalized for non-Gaussian distribution by noting that $\mathrm{V}_{e}(\boldsymbol{x})$ is equal to a particular transformation of the entropy $\mathrm{H}(\boldsymbol{z})$ when $\boldsymbol{z}$ is Gaussian. Specifically, Shannon (1948) defined the entropy power $\mathrm{N}(\boldsymbol{z})$ of a vector $\boldsymbol{z}$ with entropy $\mathrm{H}(\boldsymbol{z})$ to be

$$
\mathrm{N}(\boldsymbol{z}):=\frac{1}{2 \pi e} \exp \left(\frac{2}{n_{\boldsymbol{z}}} \mathrm{H}(\boldsymbol{z})\right),
$$

which for $\boldsymbol{z} \sim \mathbb{N}\left(\boldsymbol{\mu}_{\boldsymbol{z}}, \boldsymbol{\Sigma}_{\boldsymbol{z}}\right)$ implies $\mathrm{N}(\boldsymbol{z})=\left|\boldsymbol{\Sigma}_{\boldsymbol{z}}\right|^{1 / n_{\boldsymbol{z}}}$. Similarly, the conditional entropy power of $\boldsymbol{z}$ given $\boldsymbol{y}$ is $\mathrm{N}(\boldsymbol{z} \mid \boldsymbol{y})=\left|\boldsymbol{\Sigma}_{\boldsymbol{z} \mid \boldsymbol{y}}\right|^{1 / n_{\boldsymbol{z}}}$. Note that, unlike entropy which can be negative (for continuous variables), entropy power is always non-negative, and is therefore a more appealing measure of uncertainty. Thus, $\mathrm{IG}_{\boldsymbol{z}}(\boldsymbol{y})$ can be defined for non-Gaussian distribution as in (2.8), replacing the effective variance with entropy power. It can also be expressed in terms of mutual information using the following transformation:

$$
\mathrm{IG}_{\boldsymbol{z}}(\boldsymbol{y})=\left(1-\exp \left(-\frac{2}{n_{\boldsymbol{z}}} \mathrm{I}(\boldsymbol{y}, \boldsymbol{z})\right)\right) 100
$$

Hence $\operatorname{IG}_{\boldsymbol{z}}(\boldsymbol{y})$ is a simple modification of the transformation in (2.5) that allows information gains to be compared for vectors of different dimensions.

In the context of DSGE models, one is often interested in the information content of one or more observed variables with respect to a particular latent variable. Hence, the relevant information gain measure is of the form $\operatorname{IG}_{\boldsymbol{z}^{j}}\left(\boldsymbol{y}^{i}\right)$, where $\boldsymbol{z}^{j}$ is a $n_{\boldsymbol{z}^{j}}$ sub-vector of $\boldsymbol{z}$ containing the realization of the latent variable we are interested in, and $\boldsymbol{y}^{i}$ is a $n_{\boldsymbol{y}^{i}}$ sub-vector of $\boldsymbol{y}$ containing the observations of the variable or variables whose information content we want to assess. The required quantities, i.e. entropy (2.1) and mutual information (2.4), are obtained in exactly the same way as before, replacing the joint distributions with their marginal counterparts. Furthermore, now we can distinguish between conditional and unconditional information gains from knowing $\boldsymbol{y}^{i}$ with respect to $\boldsymbol{z}^{j}$. The unconditional information gain is given as before by $\operatorname{IG}_{\boldsymbol{z}^{j}}\left(\boldsymbol{y}^{i}\right)$ and measures the reduction in uncertainty about $\boldsymbol{z}^{j}$ due to observing $\boldsymbol{y}^{i}$ relative to observing no data at all. It is often more interesting to know the marginal contribution of $\boldsymbol{y}^{i}$, given the information about $\boldsymbol{z}^{j}$ contained in other observed 
variables. One way to define a conditional information gain of $\boldsymbol{y}^{i}$ with respect to $\boldsymbol{z}^{j}$, given $\overline{\boldsymbol{y}}^{i}:=\boldsymbol{y} \backslash \boldsymbol{y}^{i}$ is to replace the mutual information $\mathrm{I}\left(\boldsymbol{y}^{i}, \boldsymbol{z}^{j}\right)$ in (2.10) with the conditional mutual information $\mathrm{I}\left(\boldsymbol{y}^{i}, \boldsymbol{z}^{j} \mid \overline{\boldsymbol{y}}^{i}\right)=\mathrm{H}\left(\boldsymbol{z}^{j} \mid \overline{\boldsymbol{y}}^{i}\right)-\mathrm{H}\left(\boldsymbol{z}^{j} \mid \boldsymbol{y}\right)$; this would tell us how much of the uncertainty about $\boldsymbol{z}^{j}$ that remains after $\overline{\boldsymbol{y}}^{i}$ is observed is removed by observing also $\boldsymbol{y}^{i}{ }^{9}$ Note, however, that the gains would be relative to the conditional uncertainty about $\boldsymbol{z}^{j}$ given $\overline{\boldsymbol{y}}^{i}$. Therefore, that measure is not comparable to $\operatorname{IG}_{\boldsymbol{z}^{j}}\left(\boldsymbol{y}^{i}\right)$ in (2.10), which is in terms of percent of the unconditional uncertainty about $\boldsymbol{z}^{j}$. A conditional measure which is comparable to (2.8) in the Gaussian case can be defined as

$$
\mathrm{IG}_{\boldsymbol{z}^{j}}\left(\boldsymbol{y}^{i} \mid \overline{\boldsymbol{y}}^{i}\right)=\left(\frac{\left|\boldsymbol{\Sigma}_{\boldsymbol{z}^{j} \mid \overline{\boldsymbol{y}}^{i}}\right|^{1 / n_{\boldsymbol{z}^{j}}}-\left|\boldsymbol{\Sigma}_{\boldsymbol{z}^{j} \mid \boldsymbol{y}}\right|^{1 / n_{\boldsymbol{z}^{j}}}}{\left|\boldsymbol{\Sigma}_{\boldsymbol{z}^{j}}\right|^{1 / n_{\boldsymbol{z}^{j}}}}\right) 100
$$

The interpretation of $\mathrm{IG}_{\boldsymbol{z}^{j}}\left(\boldsymbol{y}^{i} \mid \overline{\boldsymbol{y}}^{i}\right)$ is the following: it shows the amount of uncertainty about $\boldsymbol{z}^{j}$ left after observing $\overline{\boldsymbol{y}}^{i}$ that is removed by observing also $\boldsymbol{y}^{i}$, as a percent of the unconditional uncertainty about $\boldsymbol{z}^{j}$. As before, for nonGaussian distributions the (conditional) effective variances are replaced with the respective (conditional) entropy powers.

Even though the information gain measures in (2.8) and (2.11) are defined with respect to the $T$-dimensional vector of all realizations of the latent variable, we can similarly measure information gains with respect to particular subsets of realizations. For instance, we can define information gains with respect to individual realizations of the latent variable. In that case we use the marginal conditional distributions of the realizations. When the distribution is Gaussian, the conditional variances which appear in the information gain measures can can be obtained by running the Kalman smoother for different combinations of observed variables. Note, however, that the Kalman smoother only provides the diagonal elements of the conditional covariance matrices in (2.8) and (2.11). In general, these matrices have non-zero off-diagonal entries since the elements of $\boldsymbol{z}^{j}$ are conditionally dependent, even if the latent variable itself is an i.i.d. process.

9. The notation $A=B \backslash C$ is used to define $A$ as the subset of $B$ that excludes the set $C$. 
The use of the information gain measures presented above can be summarized as follows: the unconditional measure (2.8) tells us how informative a set of observed variables is as a whole with respect to a given unobserved endogenous variable or exogenous shock. If $\operatorname{IG}_{\boldsymbol{z}^{j}}(\boldsymbol{y}) \approx 0$ the information about $\boldsymbol{z}^{j}$ after observing $\boldsymbol{y}$ is nearly the same as prior to observing any data. For instance, saying that standard macroeconomic variables are not very informative about news shocks can be expressed as the unconditional information gains of such variables (as a set) with respect to news shocks being close to zero. On the other hand, if $\operatorname{IG}_{\boldsymbol{z}^{j}}(\boldsymbol{y})=100$, observing $\boldsymbol{y}$ is sufficient to completely recover the realizations of the variable represented by $\boldsymbol{z}^{j}$. The conditional information gain measure (2.11) can be used to determine how much of the overall information content of $\boldsymbol{y}$ is contributed by each individual variable or subsets of variables. Therefore, the claim that asset prices contribute a lot of additional information about news shocks can be verified by showing that the information gains of asset prices with respect to news shocks conditional on standard macroeconomic variables are large. In general, by comparing conditional information gains, one could rank observed variables in terms of their relative informativeness with respect to each latent variable. In the remainder of this section I discuss how to measure the relative importance of the observed variables with respect to the unknown parameters of the model.

\subsection{Information about parameters}

The purpose of this section is to evaluate the contribution of each observed variable in terms of the amount of information they provide about the parameter vector $\boldsymbol{\theta}$ as a whole and each individual parameter. I approach this as a missing data problem (see e.g. Dempster et al. (1977) and Palm and Nijman (1984)), and compare the expected information content of complete and incomplete samples. In the present context a complete sample means observing an $n_{\boldsymbol{y}_{T}}$ vector $\boldsymbol{y}_{T}$, while an incomplete sample means observing $\overline{\boldsymbol{y}}_{T}^{i}$, that is, all variables except the one indexed by $i$. Intuitively, the distribution of the incomplete sample is less informative than the distribution of complete 
sample in the sense that the uncertainty about $\boldsymbol{\theta}$ is reduced to a lesser extent as a consequence of observing $\overline{\boldsymbol{y}}_{T}^{i}$ compared to observing $\boldsymbol{y}_{T}$ (see Rao (2002, p.331)). ${ }^{10}$ A standard measure of the expected amount of information contained in a distribution is the Fisher information matrix (FIM). Asymptotically, i.e. as $T$ tends to infinity, the inverse of the FIM is equal to the covariance matrix of the distribution of the ML estimator of $\boldsymbol{\theta}$. Hence, the expected loss of information can be measured by comparing the asymptotic variances of MLE using complete and incomplete samples. Furthermore, by the CramérRao theorem the inverse of FIM is a lower bound on the covariance matrix of any unbiased estimator of $\boldsymbol{\theta}$. Thus, the loss of information can also be assessed as a function of the sample size, by measuring the differences between CramérRao lower bounds with complete and incomplete samples.

For consistency with the previous section, I evaluate the contributions of observables in terms of efficiency gains, i.e. the reduction in expected estimation uncertainty about parameters when a variable (or a group of variables) is observed, relative to when it is not observed. Specifically, let $\boldsymbol{\Omega}_{\boldsymbol{\theta}}(\boldsymbol{y})$ and $\boldsymbol{\Omega}_{\boldsymbol{\theta}}\left(\overline{\boldsymbol{y}}^{i}\right)$ be the (asymptotic or finite-sample) CRLBs for $\boldsymbol{\theta}$ associated with the complete and incomplete samples. Note that, for large $T$, the MLE of $\boldsymbol{\theta}$ is approximately gaussian random vector with mean equal to the true value of $\boldsymbol{\theta}$, and covariance matrix given by the CRLB. Hence, $\left|\boldsymbol{\Omega}_{\boldsymbol{\theta}}\right|^{1 / n_{\boldsymbol{\theta}}}$ can be interpreted as the largesample approximation of the entropy power of the MLE of $\boldsymbol{\theta}$. Following the discussion in the previous section, I define the efficiency gain with respect to $\boldsymbol{\theta}$ from observing $\boldsymbol{y}^{i}$ relative to observing $\overline{\boldsymbol{y}}^{i}$ as follows:

$$
\mathrm{EG}_{\boldsymbol{\theta}}\left(\boldsymbol{y}^{i} \mid \overline{\boldsymbol{y}}^{i}\right)=\left(\frac{\left|\boldsymbol{\Omega}_{\boldsymbol{\theta}}\left(\overline{\boldsymbol{y}}^{i}\right)\right|^{1 / n_{\boldsymbol{\theta}}}-\left|\boldsymbol{\Omega}_{\boldsymbol{\theta}}(\boldsymbol{y})\right|^{1 / n_{\boldsymbol{\theta}}}}{\left|\boldsymbol{\Omega}_{\boldsymbol{\theta}}\left(\overline{\boldsymbol{y}}^{i}\right)\right|^{1 / n_{\boldsymbol{\theta}}}}\right) 100 .
$$

The interpretation is similar to that of the information gains in the previous section. $\mathrm{EG}_{\boldsymbol{\theta}}\left(\boldsymbol{y}^{i} \mid \overline{\boldsymbol{y}}^{i}\right)$ shows the increase in (asymptotic) efficiency of the MLE of $\boldsymbol{\theta}$ due to observing $\boldsymbol{y}^{i}$ as a percent of the estimation efficiency when only

10. See Meng and Xie (2014) for an interesting discussion of why this is true for likelihood based estimation approaches, but not in general. 
$\overline{\boldsymbol{y}}^{i}$ is observed. I use efficiency gain instead of information gain to emphasize the fact that, unlike the previous section, the gains here are in terms of the uncertainty associated with the distribution of the estimator of $\boldsymbol{\theta}$, instead of the parameter itself, which is non-random.

Wei $(1978 \mathrm{a}, \mathrm{b})$ uses a similar measure to assess the information loss due to aggregation of time series. The only difference is that he does not exponentiate the determinants of the asymptotic covariance matrices of MLE for aggregated and disaggregated samples. As explained earlier, the measure in (2.12) has the advantage of being comparable for vectors of different sizes. In particular, suppose we are interested in the marginal contribution of information from a variable with respect to individual parameters. Let $\Omega^{k, k}$ be the $k$-th diagonal element of $\boldsymbol{\Omega}^{k, k}$, i.e. the CRLB for $\theta_{k}$. Then, the efficiency gain with respect to $\theta_{k}$ from observing $\boldsymbol{y}^{i}$ is given by

$$
\mathrm{EG}_{\theta_{k}}\left(\boldsymbol{y}^{i} \mid \overline{\boldsymbol{y}}^{i}\right)=\left(\frac{\boldsymbol{\Omega}_{\boldsymbol{\theta}}^{k, k}\left(\overline{\boldsymbol{y}}^{i}\right)-\boldsymbol{\Omega}_{\boldsymbol{\theta}}^{k, k}(\boldsymbol{y})}{\boldsymbol{\Omega}_{\boldsymbol{\theta}}^{k, k}\left(\overline{\boldsymbol{y}}^{i}\right)}\right) 100 .
$$

An equivalent measure, formulated in terms of efficiency loss instead of efficiency gain, is used in Palm and Nijman (1984) to assess the loss of efficiency with respect to individual parameters due to missing observations in dynamic regression models. More broadly, FIM-based criteria similar to (2.12) and (2.13) are widely used in the experiment design literature to select an optimal design, i.e. a design which maximizes, according to a given criterion, the amount of information that an experimenter can expect to learn about the parameters through an experiment (see e.g. Silvey (1980) and Pronzato and Pázman (2013)).

\section{Asset prices and news shocks}

This section evaluates the contribution of information by asset price variables in DSGE models containing news shocks. In particular, I am interested in validity of the following two claims: (1) standard macroeconomic variables are uninformative about news shocks; and (2) asset prices contribute a lot of 
information about news shocks. Clearly it is not possible to give a single general answer as to whether these statements are true or not under all circumstances. Instead, the main purpose here is to demonstrate how the measures from Section 2 can be used to study the information properties of observables in the context of a particular environment. I consider two versions of the standard real business cycle model augmented with real rigidities in consumption, investment, capital utilization, and wage setting. The first version is taken from SchmittGrohé and Uribe (2012) (SGU henceforth) who estimate it without asset price data. The second version is from Avdjiev (2016) and differs from the SGU specification mainly in the way news shocks are introduced into the model and in the use of asset price data for estimation. In what follows, I first outline the main features of each model, and then apply the information measures presented in Section 2 to assess the contribution of information by asset prices with respect to news shocks in these models.

\subsection{Schmitt-Grohé and Uribe (2012) model}

The model economy is populated by a continuum of identical agents each maximizing the following lifetime utility function

$$
\mathrm{E}_{0} \sum_{t=0}^{\infty} \beta^{t} \zeta_{t} \frac{\left[C_{t}-b C_{t-1}-\psi H_{t}^{\theta} S_{t}\right]^{1-\sigma}-1}{1-\sigma},
$$

where $\zeta_{t}$ is a preference shock, $C_{t}$ is consumption, $H_{t}$ is hours worked, and $S_{t}$ is a geometric average of past habit-adjusted consumption: $S_{t}=\left(C_{t}-b C_{t-1}\right)^{\gamma} S_{t-1}^{1-\gamma}$. The household budget constraint is given by

$$
C_{t}+A_{t} I_{t}+T_{t}=W_{t} H_{t}+r_{t} u_{t} K_{t}+P_{t},
$$

where $A_{t}$ is a non-stationary investment specific productivity growing at rate $\mu_{t}^{a}$. The variable $T_{t}$ denotes lump-sum taxes, $W_{t}$ is the wage rate, $r_{t}$ is rental rate of capital, $u_{t}$ is capacity utilization, $K_{t}$ is capital stock, and $P_{t}$ denotes profit. The law of motion for capital stock is

$$
K_{t+1}=\left(1-\delta\left(u_{t}\right)\right) K_{t}+z_{t}^{I} I_{t}\left[1-\frac{\kappa}{2}\left(\frac{I_{t}}{I_{t-1}}-\mu^{I}\right)\right]
$$


where $I_{t}$ is investment, $\delta$ is the rate of depreciation - an increasing function of the rate of capacity utilization $u_{t}, \kappa$ is a parameter that determines the convexity of the investment adjustment cost function, $\mu^{I}$ is is the steady state growth rate of investment, and $z_{t}^{I}$ is a stationary investment specific productivity shock.

Final good $Y_{t}$ is produced with the following production function:

$$
Y_{t}=z_{t}\left(u_{t} K_{t}\right)^{\alpha_{k}}\left(X_{t} H_{t}\right)^{\alpha_{h}}\left(X_{t} L\right)^{1-\alpha_{k}-\alpha_{h}},
$$

where $z_{t}$ is a stationary neutral productivity shock, $L$ is a fixed factor of production, ${ }^{11}$ and $X_{t}$ is a non-stationary neutral productivity growing at rate $\mu_{t}^{x}$.

The labor input $H_{t}$, which is used by final-good-producing firms, is obtained by combining differentiated labor services $H_{j t}$ supplied by monopolistically competitive labor unions,

$$
H_{t}=\left[\int_{0}^{1} H_{j t}^{\frac{1}{1+\mu_{t}}} d j\right]^{1+\mu_{t}}
$$

where $\mu_{t}$ is a wage markup shock with steady state value $\mu>1$.

Each period the government spends an amount $G_{t}$, financed with lump-sum taxes. $G_{t}$ is determined exogenously and is assumed to grow at rate $X_{t}^{G}$, defined as a smoothed version of the trend in $Y_{t}$, given by $X_{t}^{Y}=X_{t} A_{t}^{\alpha_{k} /\left(\alpha_{k}-1\right)}$.

Each of the seven shocks is driven by three independent innovations, two anticipated and one unanticipated. More precisely, the process governing shock $x_{t}$ for $x=\mu^{a}, \mu^{x}, z^{I}, z, \mu, g, \zeta$ is given by

$$
\ln \left(x_{t} / x\right)=\rho_{x} \ln \left(x_{t-1} / x\right)+\sigma_{x}^{0} \varepsilon_{x, t}^{0}+\sigma_{x}^{4} \varepsilon_{x, t-4}^{4}+\sigma_{x}^{8} \varepsilon_{x, t-8}^{8},
$$

where $\varepsilon_{x, t}^{j}$ for $j=0,4,8$ are independent standard normal random variables. The anticipated innovations $\varepsilon_{x, t-4}^{4}$ and $\varepsilon_{x, t-8}^{8}$ are known to agents in periods $t-4$ and $t-8$, respectively. Thus, they are interpreted as news shocks.

11. The fixed factor of production generates decreasing returns to scale in the two variable factors of production $K_{t}$ and $H_{t}$. As shown by Jaimovich and Rebelo (2009) this allows for a positive response of the value of the firm to future expected increases in productivity. 
SGU report results based on estimation of the model using quarterly data on seven macroeconomic series: the growth rate of per capita real GDP $\left(y_{t}:=\triangle \ln Y_{t}\right)$ contaminated with a measurement error, the growth rates of real consumption $\left(c_{t}:=100 \triangle \ln C_{t}\right)$, real investment $\left(i_{t}:=100 \triangle \ln A_{t} I_{t}\right)$, real government expenditure $\left(g_{t}:=100 \triangle \ln G_{t}\right)$, and hours $\left(h_{t}:=100 \triangle \ln H_{t}\right)$, and the growth rates of the relative price of investment $\left(a_{t}:=100 \triangle \ln A_{t}\right)$ and of total factor productivity $\left(t f p_{t}:=100 \triangle \ln T F P_{t}\right){ }^{12}$

In addition to these variables, the model makes predictions about the behavior of two asset price variables: the value of the firm and the risk-free real interest rate. The value of the firm $V^{F}$ can be computed as

$$
V_{t}^{F}=Y_{t}-W_{t} H_{t}-A_{t} I_{t}+\beta E_{t} \frac{\Lambda_{t+1}}{\Lambda_{t}} V_{t+1}^{F}
$$

where $\Lambda_{t}$ is the Lagrange multiplier associated with the household's budget constraint. The risk-free real interest rate is given by

$$
R_{t}=\frac{1}{\beta} \frac{\Lambda_{t}}{E_{t} \Lambda_{t+1}}
$$

In estimation, the value of the firm can be matched to stock price data. In particular, $v_{t}^{f}:=\triangle \ln V_{t}^{F}$ can be represented with the growth rate of the real per capita value of the stock market. Similarly, data on $r_{t}:=\log R_{t}$ can be obtained by deflating the nominal rate on the three-month Treasury bill by the inflation rate implied by the GDP deflator.

The main reason SGU give for not using stock price data in the estimation is that models such as the one described here are not well suited for explaining the behavior of stock prices. Avdjiev (2016), whose model I consider in Section 3.2 , uses data on both $v^{f}$ and $r$, but introduces measurement errors in the series in order to account for discrepancies between the model variables and their empirical counterparts. His argument is that, even though imperfectly

12. The growth rate of total factor productivity in the model is given by $t f p_{t}=$ $100\left(\triangle \ln z_{t}+\left(1-\alpha_{k}\right) \ln \mu_{t}^{x}\right)$. 
measured, the asset price implications of the model contain useful information about news shocks that standard macroeconomic variables alone do not.

Here, I abstract from the issue of whether $v^{f}$ and $r$ have adequate empirical counterparts. The question I am interested in is whether observing these model variables, if such data were available, would provide a significant amount of additional information with respect to news shocks. This question is addressed next.

3.1.1. Information about news shocks. Following the notation in Section 2, let $\boldsymbol{y}$ be a vector collecting the observations of all observable variables (including $v^{f}$ and $r$ ), and $\overline{\boldsymbol{y}}$ be the vector of observations of the variables used in the baseline estimation of SGU, i.e. $\overline{\boldsymbol{y}}=\boldsymbol{y} \backslash\left(v^{f}, r\right)$. Note that $\boldsymbol{y}$ is a $T \times 9$ dimensional vector, and $\overline{\boldsymbol{y}}$ is a $T \times 7$ dimensional vector. The purpose of this section is to evaluate the information gains from observing $v^{f}, r$, or both, with respect to news shocks, which in this model are represented by the anticipated innovations to the seven fundamental shocks. There are 14 such innovations, each one of which is a $T$ dimensional vector. I set $T=207$, which is the sample size in SGU.

SGU solve the model by log-linear approximation of the equilibrium conditions around steady state. The linearity of the solution together with the assumption that the structural innovations and the measurement error in output growth are Gaussian, implies that the joint distribution of (any subset of) the innovations, shocks, state and observed variables is also Gaussian. This fact is used in SGU to compute the likelihood function required for estimation of the model parameters with classical and Bayesian methods. In addition, it implies that the information gains measures discussed in Section 2.1 can be computed analytically for a given set of parameter values. In what follows I parameterize the model using the maximum likelihood estimates reported in Schmitt-Grohé and Uribe (2012) (see Table A.1 in the Appendix). As I explain in more details at the end of this section, the main conclusions do not change in any significant way if the mean or the mode of the posterior distribution are used instead. 


\begin{tabular}{llrrrrrr}
\hline \multicolumn{1}{c}{ innovation } & $\mathrm{IG}(\overline{\boldsymbol{y}})$ & $\mathrm{IG}\left(v^{f}, r \mid \overline{\boldsymbol{y}}\right)$ & $\mathrm{IG}\left(v^{f} \mid \overline{\boldsymbol{y}}\right)$ & $\mathrm{IG}(r \mid \overline{\boldsymbol{y}})$ & $\mathrm{IG}\left(v^{f}\right)$ & $\mathrm{IG}(r)$ \\
\hline$\varepsilon_{\mu^{a}}^{0}$ & non-stat. investment-specific prod. & 26.3 & 3.7 & 3.5 & 0.1 & 0.2 & 0.1 \\
$\varepsilon_{\mu^{a}}^{4}$ & non-stat. investment-specific prod. 4q & 38.4 & 3.2 & 3.0 & 0.3 & 0.1 & 0.1 \\
$\varepsilon_{\mu^{a}}^{8}$ & non-stat. investment-specific prod. 8q & 34.0 & 3.3 & 3.1 & 0.3 & 0.1 & 0.1 \\
$\varepsilon_{\mu^{x}}^{0}$ & non-stat. neutral prod. & 26.9 & 19.9 & 14.6 & 4.3 & 18.4 & 2.2 \\
$\varepsilon_{\mu^{x}}^{4}$ & non-stat. neutral prod. 4q & 2.1 & 8.6 & 2.3 & 5.0 & 0.6 & 1.4 \\
$\varepsilon_{\mu^{x}}^{8}$ & non-stat. neutral prod. 8q & 2.3 & 8.9 & 2.0 & 5.6 & 0.6 & 1.6 \\
$\varepsilon_{\boldsymbol{z}^{I}}^{0}$ & stat. investment-specific prod. & 84.0 & 9.5 & 7.0 & 5.0 & 0.9 & 0.9 \\
$\varepsilon_{z^{I}}^{4}$ & stat. investment-specific prod. 4q & 10.3 & 23.3 & 17.8 & 8.3 & 0.8 & 1.7 \\
$\varepsilon_{z^{I}}^{8}$ & stat. investment-specific prod. 8q & 16.5 & 33.3 & 26.7 & 11.1 & 1.6 & 2.8 \\
$\varepsilon_{z}^{0}$ & stat. neutral prod. & 71.7 & 6.5 & 2.6 & 3.3 & 42.2 & 8.5 \\
$\varepsilon_{z}^{4}$ & stat. neutral prod. 4q & 2.6 & 11.9 & 1.5 & 8.9 & 0.8 & 2.3 \\
$\varepsilon_{z}^{8}$ & stat. neutral prod. 8q & 2.7 & 12.0 & 1.5 & 9.0 & 0.8 & 2.3 \\
$\varepsilon_{\mu}^{0}$ & wage markup & 9.7 & 27.4 & 1.9 & 21.6 & 3.4 & 0.6 \\
$\varepsilon_{\mu}^{4}$ & wage markup 4q & 52.9 & 5.0 & 1.7 & 3.5 & 15.1 & 42.3 \\
$\varepsilon_{\mu}^{8}$ & wage markup 8q & 34.4 & 4.6 & 2.3 & 2.5 & 9.8 & 27.5 \\
$\varepsilon_{g}^{0}$ & government spending & 28.8 & 2.6 & 0.3 & 2.0 & 0.7 & 0.1 \\
$\varepsilon_{g}^{4}$ & government spending 4q & 47.9 & 1.9 & 0.5 & 1.1 & 0.6 & 1.8 \\
$\varepsilon_{g}^{8}$ & government spending 8q & 18.6 & 0.9 & 0.3 & 0.5 & 0.3 & 0.7 \\
$\varepsilon_{\zeta}^{0}$ & preference & 16.3 & 5.3 & 1.6 & 3.2 & 0.6 & 0.1 \\
$\varepsilon_{\zeta}^{4}$ & preference 4q & 16.0 & 1.3 & 0.8 & 0.2 & 0.3 & 0.9 \\
$\varepsilon_{\zeta}^{8}$ & preference 8q & 60.7 & 2.7 & 1.2 & 0.7 & 1.2 & 3.4 \\
\hline
\end{tabular}

Note: $\overline{\boldsymbol{y}}$ contains all observed variables $(\boldsymbol{y})$ except asset prices $\left(v^{f}\right.$ and $\left.r\right)$. The information gain $\operatorname{IG}_{\varepsilon}(\boldsymbol{x})$ measures the reduction in uncertainty about variable $\varepsilon$ due to observing variable $\boldsymbol{x}$, in per cent of the prior (unconditional) uncertainty. The conditional information gain $\mathrm{IG}_{\varepsilon}(\boldsymbol{x} \mid \boldsymbol{z})=\mathrm{IG}_{\varepsilon}(\boldsymbol{x}, \boldsymbol{z})-\mathrm{IG}_{\varepsilon}(\boldsymbol{z})$ measures the additional reduction in uncertainty from observing $\boldsymbol{x}$ given that $\boldsymbol{z}$ is observed.

TABLE 1. Information content of asset prices: innovations

Table 1 presents the results for all innovations - anticipated and unanticipated. The first two columns show the unconditional gains from observing $\overline{\boldsymbol{y}}$, and the additional gains from observing both $v^{f}$ and $r$, conditional on $\overline{\boldsymbol{y}}$ being observed. Note that the information gains from observing all nine variables are given by $\mathrm{IG}_{\varepsilon}(\boldsymbol{y})=\mathrm{IG}_{\varepsilon}(\overline{\boldsymbol{y}})+\mathrm{IG}_{\varepsilon}\left(v^{f}, r \mid \overline{\boldsymbol{y}}\right)$. The results show that none of the innovations, anticipated or unanticipated, can be fully recovered from the observed variables, even when $v^{f}$ and $r$ are among them. The largest reduction of uncertainty is with respect to the unanticipated stationary investment-specific productivity innovations $\left(\varepsilon_{z^{I}}^{0}\right)$ - by about $94 \%$, and the unanticipated stationary neutral productivity innovations $\left(\varepsilon_{z}^{0}\right)$ - by about $78 \%$. In terms of anticipated innovations, i.e. news shocks, the information gains are largest with respect to the 8-quarter ahead preference shock - about 
$63 \%$, and the 4-quarter ahead wage markup shock - about 58\%. However, the contribution of information by asset prices with respect to these shocks is fairly modest. The largest gains due to observing $v^{f}$ and $r$ are with respect to news about the stationary investment-specific productivity shocks. They are about $23 \%$ with respect to $\varepsilon_{z^{I}}^{4}$ and $33 \%$ with respect to $\varepsilon_{z^{I}}^{8}$. Other news shocks for which the contribution of asset prices is non-trivial are the stationary and non-stationary neutral productivity shocks. The gains are about $12 \%$ and $9 \%$, respectively.

The relative contributions of the two asset price variables can seen from the third and fourth columns of the table, which report the additional gains from observing either $v^{f}$ or $r$, conditional on $\overline{\boldsymbol{y}}$ being observed. Even though both asset price variables contribute a substantial amount of information about $\varepsilon_{z^{I}}^{4}$ and $\varepsilon_{z^{I}}^{8}$, the gains from observing $v^{f}$ are significantly larger. At the same time, $r$ is the more informative of the two variables with respect to the news components of the stationary and non-stationary neutral productivity shocks.

The last two columns show the information gains from observing either $v^{f}$ or $r$, relative to having no data at all. Interestingly, the gains are very small with respect to most news shocks, including the stationary investmentspecific productivity shocks and the neutral productivity shocks. This means that almost all of the information which asset prices contribute with respect to these shocks comes from the interactions of $v^{f}$ and $r$ with variables in $\overline{\boldsymbol{y}}$. That is, the information comes from cross-moments of asset prices and macro variables rather than the own moments of asset prices. Note that the opposite is true in the case of the news components in the wage markup shock. The unconditional gains from observing $v^{f}$ or $r$ are much larger than the conditional gains. This implies that most of the information provided by either one of the asset price variables is also contained in other observed variables. ${ }^{13}$

13. The unanticipated innovation to the non-stationary neutral productivity shock $\varepsilon_{\mu^{x}}^{0}$ is an example of a third possibility - where the information gains from observing $v^{f}$ are relatively large, both conditionally and unconditionally. 
The results in Table 1 raise the question of how $v^{f}$ and $r$ compare to other observables in terms of the amount of information they provide about news shocks. To answer this question, I compute conditional information gains for each variable in $\boldsymbol{y}$. That is, I evaluate $\operatorname{IG}_{\varepsilon}\left(x \mid \boldsymbol{y}^{x}\right)$ where $x$ is one of the nine observables, and $\boldsymbol{y}^{x}$ contains all observables (including $v^{f}$ and $r$ ) except $x$. The results are shown in Figure 1. Note that hours worked and TFP each contribute more information with respect to the stationary investmentspecific productivity news shocks compared to $v^{f}$ or $r$. The relative price of investment is by far the most informative variable with respect to the news components in the non-stationary investment-specific productivity shocks, while government expenditure and consumption are, respectively, the most informative variables about government spending and preference news shocks. The anticipated innovations to the stationary neutral productivity shocks are the only news shocks for which an asset price variable, specifically the risk-free rate, contributes significantly more information than any other variable.

An important conclusion which emerges from Table 1 and Figure 1 is that the marginal contribution of information by a variable depends on which other variables are observed. Furthermore, in some cases the contribution is enhanced due to presence of other variables, while in other cases it is diminished. For instance, as we saw in Table $1, v^{f}$ alone provides very little information about $\varepsilon_{z^{I}}^{4}$ and $\varepsilon_{z^{I}}^{8}$. Conditional on observing all seven macro variables, however, the contribution of $v^{f}$ is substantial. The opposite is true with respect to $\varepsilon_{\mu^{x}}^{0}$ and $\varepsilon_{z}^{0}$. This suggests that there exists a degree of positive information complementarity between $v^{f}$ and (some of the) macro variables in the first case, and negative complementarity, or information redundancy, in the second. To find out how $v^{f}$ interacts with each one of the macro variables, it is helpful to define a measure of (conditional) information complementarity between two variables. Specifically, let $x$ be a member of $\overline{\boldsymbol{y}}$ and $\overline{\boldsymbol{y}}^{x}:=\overline{\boldsymbol{y}} \backslash x$. Then, the conditional information complementarity with respect to variable $\varepsilon$ between $v^{f}$ and $x$ can be defined as:

$$
\operatorname{IC}_{\varepsilon}\left(v^{f}, x \mid \overline{\boldsymbol{y}}^{x}\right)=\frac{\mathrm{IG}_{\varepsilon}\left(v^{f}, x \mid \overline{\boldsymbol{y}}^{x}\right)}{\operatorname{IG}_{\varepsilon}\left(v^{f} \mid \overline{\boldsymbol{y}}^{x}\right)+\mathrm{IG}_{\varepsilon}\left(x \mid \overline{\boldsymbol{y}}^{x}\right)}-1 .
$$




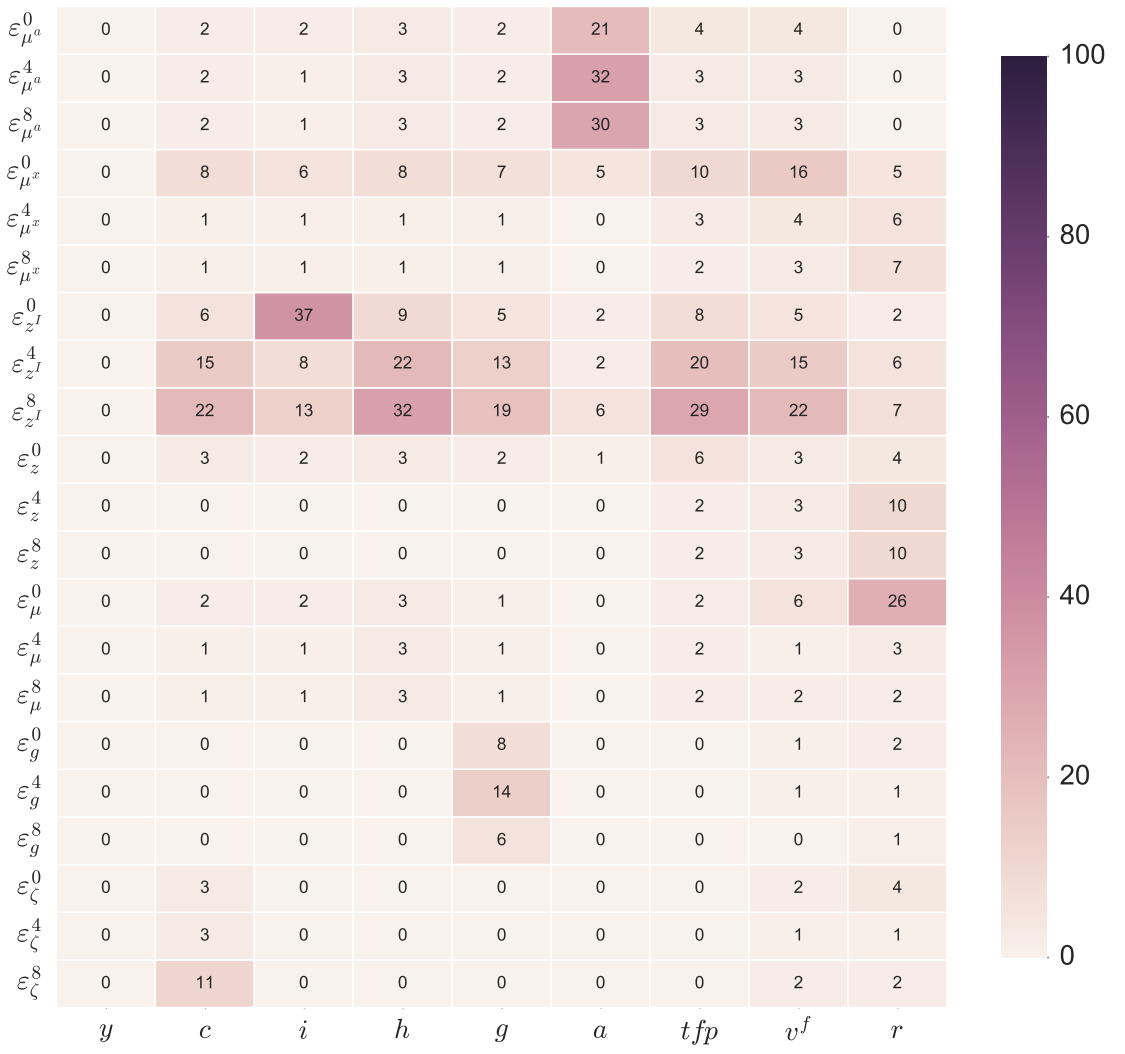

Figure 1: Conditional information gains at MLE of SGU.

Negative values indicate negative complementarity, or information redundancy, between $v^{f}$ and $x$, and positive values indicate positive complementarity between the two variables. Since the information gain is non-negative, we have $\operatorname{IC}_{\varepsilon}\left(v^{f}, x \mid \overline{\boldsymbol{y}}^{x}\right) \geq-1 / 2$, with equality when $v^{f}$ and $x$ are (conditionally on $\left.\overline{\boldsymbol{y}}^{x}\right)$ functionally dependent, in which case $\mathrm{IG}_{\varepsilon}\left(v^{f}, x \mid \overline{\boldsymbol{y}}^{x}\right)=\mathrm{IG}_{\varepsilon}\left(v^{f} \mid \overline{\boldsymbol{y}}^{x}\right)=$ $\mathrm{IG}_{\varepsilon}\left(x \mid \overline{\boldsymbol{y}}^{x}\right) .{ }^{14}$ A lack of information complementarity, i.e. $\mathrm{IC}_{\varepsilon}\left(v^{f}, x \mid \overline{\boldsymbol{y}}^{x}\right)=0$ could occur if $v^{f}$ and $x$ are (conditionally on $\overline{\boldsymbol{y}}^{x}$ ) independent, and hence

14. Note that $\operatorname{IG}_{\varepsilon}\left(v^{f}, x \mid \overline{\boldsymbol{y}}^{x}\right) \geq \max \left(\mathrm{IG}_{\varepsilon}\left(v^{f} \mid \overline{\boldsymbol{y}}^{x}\right), \mathrm{IG}_{\varepsilon}\left(x \mid \overline{\boldsymbol{y}}^{x}\right)\right)$ and $\mathrm{IG}_{\varepsilon}\left(v^{f}, x \mid \overline{\boldsymbol{y}}^{x}\right)=0$ implies $\mathrm{IG}_{\varepsilon}\left(v^{f} \mid \overline{\boldsymbol{y}}^{x}\right)=\mathrm{IG}_{\varepsilon}\left(x \mid \overline{\boldsymbol{y}}^{x}\right)=0$. In that case $\frac{\mathrm{IG}_{\varepsilon}\left(v^{f}, x \mid \overline{\boldsymbol{y}}^{x}\right)}{\mathrm{IG}_{\varepsilon}\left(v^{f} \mid \overline{\boldsymbol{y}}^{x}\right)+\mathrm{IG}_{\varepsilon}\left(x \mid \overline{\boldsymbol{y}}^{x}\right)}=\frac{0}{0}$, which is taken to be equal to 1 . 
$\mathrm{IG}_{\varepsilon}\left(v^{f}, x \mid \overline{\boldsymbol{y}}^{x}\right)=\mathrm{IG}_{\varepsilon}\left(v^{f} \mid \overline{\boldsymbol{y}}^{x}\right)+\mathrm{IG}_{\varepsilon}\left(x \mid \overline{\boldsymbol{y}}^{x}\right)$. Note that instead of $\overline{\boldsymbol{y}}^{x}$ in (3.9) the conditioning could be with respect to any other set of variables, including the empty set which would show the unconditional complementarity between $v^{f}$ and $x$.

Using Table 1, we can determine the degree of complementarity between $v^{f}$ and $r$, conditionally on the seven macro variables. There is a positive complementarity with respect to the preference shock, the stationary and nonstationary neutral productivity shocks, and the government spending shock. At the same time there is a negative complementarity, or redundancy of information, with respect to the stationary and non-stationary investmentspecific news shocks, and wage markup shock. Overall, the degree of complementarity, both positive and negative, is relatively week.

Figures A.1 - A.4 in the Appendix show results for conditional and unconditional information complementarity between $v^{f}$ and $r$ and each one of the macro variables. The main findings can be summarized as follows: (1) both $v^{f}$ and $r$ display very strong conditional complementarity with $h$ and $t f p$, and relatively weaker, but still significant complementarity with $c$; (2) The complementarity is positive with respect to the news components in the stationary and non-stationary investment specific shocks, and, in the case of $h$ and $c$, the stationary and non-stationary neutral productivity shocks. The complementarity is negative with respect to news about the wage markup and preference shocks; (3) The magnitude and even the sign of the information complementarity may change depending on the conditioning variables. For instance, unconditionally, $v^{f}$ is strongly complementary only with $t f p$, and the complementarity is positive with respect to all news shocks except the two neutral productivity news shocks. $r$, on the other hand, is unconditionally strongly complementary primarily with $h$, and the complementarity is positive with respect to all news except the wage markup news shocks; (4) Conditionally, there is zero information complementarity between either $v^{f}$ or $r$, on one hand, and $y$, on the other. 
As noted earlier, it is not possible to recover without error the 21 anticipated and unanticipated innovations from either 7 or 9 observed variables. In fact, in many cases the information gains are small, meaning that the posterior uncertainty remains very close to the prior uncertainty. There are, however, only 7 structural shocks and it is natural to expect that they are easier to recover than the innovations. This is indeed the case, as can be seen in Table 2 , which shows results from the same analysis as in Table 1, now applied to the structural shocks. With 9 observed variables the information gains exceed $97 \%$ for 5 of the shocks. The two shocks for which the gains are relatively small are the non-stationary neutral productivity - around $48 \%$, and the stationary neutral productivity - around $82 \%$ with 9 observed variables. The asset price variables provide a significant amount of additional information with respect to the non-stationary neutral productivity and the stationary investment-specific productivity shocks. Most of these gains are due to information in $v^{f}$. The information gains are $100 \%$ with respect to the non-stationary investmentspecific productivity, meaning that the realizations of $\mu_{t}^{a}$ can be completely recovered from the observed variables. This is a consequence of the assumption that the technology which converts consumption into investment goods is linear. As a result, in equilibrium the growth rate of the relative price of investment is equal to non-stationary investment-specific productivity shock. Hence, observing the price of investment alone is sufficient to fully recover $\mu_{t}^{a}$ for all $t$. None of the other shocks can be fully recovered from the observed variable, although the information gains exceed $99 \%$ in the case of wage markup, government expenditures, and preference shocks.

3.1.2. Information about parameters. This section evaluates the information content of asset prices with respect to the news shock-related parameters in the model. It supplements the analysis in Schmitt-Grohé and Uribe (2012) who show that the parameters are identified from the second-order moments 


\begin{tabular}{llrcrrrr}
\hline \multicolumn{1}{c}{ shock } & $\mathrm{IG}(\overline{\boldsymbol{y}})$ & $\mathrm{IG}\left(v^{f}, r \mid \overline{\boldsymbol{y}}\right)$ & $\mathrm{IG}\left(v^{f} \mid \overline{\boldsymbol{y}}\right)$ & $\mathrm{IG}(r \mid \overline{\boldsymbol{y}})$ & $\mathrm{IG}\left(v^{f}\right)$ & $\mathrm{IG}(r)$ \\
\hline$\mu^{a}$ & nonstationary investment-specific prod. & 100.0 & 0.0 & 0.0 & 0.0 & 0.2 & 0.2 \\
$\mu^{x}$ & nonstationary neutral prod. & 30.8 & 16.8 & 12.2 & 4.1 & 19.2 & 2.6 \\
$z^{I}$ & stationary investment-specific prod. & 86.4 & 11.0 & 10.6 & 2.5 & 2.1 & 2.9 \\
$z$ & stationary neutral prod. & 76.5 & 5.8 & 4.1 & 1.5 & 43.7 & 8.8 \\
$\mu$ & wage markup & 98.2 & 1.4 & 0.8 & 1.0 & 28.7 & 68.1 \\
$g$ & government spending & 98.8 & 0.3 & 0.2 & 0.1 & 1.5 & 1.9 \\
$\zeta$ & preference & 98.3 & 1.3 & 0.7 & 0.5 & 2.2 & 3.7 \\
\hline
\end{tabular}

Note: see note to Table 1

TABLE 2. Information content of asset prices: shocks

of the seven variables used in estimation. ${ }^{15}$ It is clear that having additional observed variables would increase the amount of information. The purpose of the following analysis is to provide a quantitative assessment of the size of the gains from observing $v^{f}, r$, or both, and to compare them to the gains from other observables.

As discussed in Section 2.2, the information content of a variable (or a set of variables) $x$ with respect to estimated parameters is measured in terms of efficiency gains, which are computed using the parameter CRLBs with and without $x$. The differences between the values of the bounds reflect the information content of the model-impled restrictions on the joint distribution of $x$ and the other observables. Hence, parameters for which these restrictions are more informative will see a greater reduction in the values of their lower bounds, i.e. larger efficiency gains.

The results are presented in Table 3. As also discussed in Section 2.2, the gains are in terms of reduction in uncertainty as a per cent of the uncertainty conditional on observing $\overline{\boldsymbol{y}}$. Overall, the efficiency gains are substantial, in the order of between $90 \%$ and $97 \%$ for parameters of news shocks when both $v^{f}$ and $r$ are included. The gains are smaller but still significant when only one of the asset price variables is observed, and tend to be larger if that variable is

15. Even though Schmitt-Grohé and Uribe (2012) de-mean the data, this does not result in loss of information since all parameters for which first-order moments are informative are assumed to be known, i.e. are calibrated and not estimated. 


\begin{tabular}{|c|c|c|c|c|}
\hline & parameter & $v^{f}, r$ & $v^{f}$ & $r$ \\
\hline$\theta$ & Frisch elasticity of labor supply & 83 & 61 & 78 \\
\hline$\gamma$ & wealth elasticity of labor supply & 51 & 35 & 28 \\
\hline$\kappa$ & investment adjustment cost & 95 & 94 & 59 \\
\hline$\delta_{2} / \delta_{1}$ & capacity utilization cost & 99 & 97 & 88 \\
\hline$b$ & habit in consumption & 75 & 66 & 27 \\
\hline$\rho_{x g}$ & government spending & 34 & 17 & 20 \\
\hline$\rho_{z}$ & AR stationary neutral productivity & 85 & 66 & 67 \\
\hline$\rho_{\mu^{a}}$ & AR non-stationary investment-specific productivity & 40 & 37 & 2 \\
\hline$\rho_{g}$ & AR government spending & 52 & 48 & 42 \\
\hline$\rho_{\mu^{x}}$ & AR non-stationary neutral productivity & 87 & 72 & 60 \\
\hline$\rho_{\mu}$ & AR wage markup & 77 & 69 & 14 \\
\hline$\rho_{\zeta}$ & AR preference & 28 & 19 & 9 \\
\hline$\rho_{z^{I}}$ & AR stationary investment-specific productivity & 96 & 92 & 78 \\
\hline$\sigma_{z}^{0}$ & std. stationary neutral productivity 0 & 87 & 59 & 83 \\
\hline$\sigma_{z}^{4}$ & std. stationary neutral productivity 4 & 93 & 73 & 72 \\
\hline$\sigma_{z}^{8}$ & std. stationary neutral productivity 8 & 90 & 73 & 64 \\
\hline$\sigma_{\mu^{a}}^{0}$ & std. non-stationary investment-specific productivity 0 & 95 & 95 & 43 \\
\hline$\sigma_{\mu^{a}}^{\mu}$ & std. non-stationary investment-specific productivity 4 & 97 & 96 & 74 \\
\hline$\sigma_{\mu^{a}}^{8}$ & std. non-stationary investment-specific productivity 8 & 96 & 96 & 68 \\
\hline$\sigma_{g}^{0}$ & std. government spending 0 & 97 & 80 & 95 \\
\hline$\sigma_{g}^{4}$ & std. government spending 4 & 91 & 89 & 52 \\
\hline$\sigma_{g}^{8}$ & std. government spending 8 & 91 & 89 & 55 \\
\hline$\sigma_{\mu^{x}}^{0}$ & std. non-stationary neutral productivity 0 & 78 & 50 & 67 \\
\hline$\sigma_{\mu^{x}}^{4}$ & std. non-stationary neutral productivity 4 & 94 & 78 & 71 \\
\hline$\sigma_{\mu^{x}}^{8}$ & std. non-stationary neutral productivity 8 & 90 & 74 & 58 \\
\hline$\sigma_{\mu}^{0}$ & std. wage markup 0 & 99 & 70 & 97 \\
\hline$\sigma_{\mu}^{4}$ & std. wage markup 4 & 90 & 84 & 52 \\
\hline$\sigma_{\mu}^{8}$ & std. wage markup 8 & 90 & 85 & 48 \\
\hline$\sigma_{\zeta}^{0}$ & std. preference 0 & 98 & 89 & 97 \\
\hline$\sigma_{\zeta}^{4}$ & std. preference 4 & 90 & 88 & 39 \\
\hline$\sigma_{\zeta}^{8}$ & std. preference 8 & 91 & 88 & 50 \\
\hline$\sigma_{z^{I}}^{0}$ & std. stationary investment-specific productivity 0 & 92 & 91 & 66 \\
\hline$\sigma_{z^{I}}^{4}$ & std. stationary investment-specific productivity 4 & 96 & 93 & 81 \\
\hline$\sigma_{z^{I}}^{8}$ & std. stationary investment-specific productivity 8 & 92 & 88 & 72 \\
\hline
\end{tabular}

Note: The efficiency gain $\mathrm{EG}_{\theta_{i}}(\boldsymbol{x} \mid \overline{\boldsymbol{y}})$, for (1) $\boldsymbol{x}=\left(v^{f}, r\right),(2) \boldsymbol{x}=v^{f}$, or (3) $\boldsymbol{x}=r$, is defined as the reduction in the value of CRLB for $\theta_{i}$ when all variables are observed, as a per cent of the value of the CRLB when all variables except those in $\boldsymbol{x}$ are observed.

TABLE 3. Efficiency gains (\%)

$v^{f}$. These results seem to suggest that asset prices are indeed very informative with respect to news shock-related parameters. However, this does not imply that $v^{f}$ and $r$ are more informative than other observables. To find out if they are, one has to compare the efficiency gains from observing asset prices to the gains from other variables. Figure 2 does that for each one of the nine variables in $\boldsymbol{y}$. Note that, unlike in Table 3 , the efficiency gains are now relative 
to eight, not seven, observables. For instance, the gains from observing $r$ are relative to observing all other variables, including $v^{f}$. As a result, they are generally much smaller than before, especially with respect to news shocks parameters. This means that once $v^{f}$ is observed, $r$ adds relatively little new information about these parameters. At the same time, the efficiency gains due to $v^{f}$ remain substantial, although not as large as in Table 3 . Comparing the results across all variables shows that $h$ and $t f p$ tend to be as informative with respect to news shocks-related parameters as $v^{f}$ and $r$. Only in the cases of the neutral productivity shocks - both stationary and non-stationary, are the asset price variables the most informative ones, with $t f p$ being close next best. Therefore, we can conclude that, although very informative about most model parameters, the two asset price variables in this model are not in any way uniquely important for the identification of news shocks-related parameters.

\begin{tabular}{|c|c|c|c|c|c|c|c|c|c|c|}
\hline$\sigma_{z}^{0}$ & 0 & 17 & 9 & 22 & 29 & 9 & 37 & 26 & 69 & \multirow{2}{*}{100} \\
\hline$\sigma_{z}^{4}$ & 0 & 41 & 30 & 41 & 32 & 8 & 64 & 74 & 73 & \\
\hline$\sigma_{z}^{8}$ & 0 & 41 & 29 & 41 & 32 & 8 & 64 & 73 & 64 & \multirow{4}{*}{80} \\
\hline$\sigma_{\mu^{a}}^{0}$ & 0 & 55 & 40 & 78 & 52 & 98 & 94 & 91 & 4 & \\
\hline$\sigma_{\mu^{a}}^{4}$ & 0 & 59 & 37 & 87 & 52 & 97 & 96 & 87 & 5 & \\
\hline$\sigma_{\mu^{a}}^{8}$ & 0 & 62 & 41 & 88 & 56 & 97 & 97 & 89 & 6 & \\
\hline$\sigma_{g}^{0}$ & 0 & 8 & 5 & 11 & 43 & 3 & 17 & 29 & 83 & \multirow{4}{*}{60} \\
\hline$\sigma_{g}^{4}$ & 0 & 58 & 32 & 68 & 64 & 6 & 85 & 81 & 20 & \\
\hline$\sigma_{g}^{8}$ & 0 & 57 & 32 & 68 & 65 & 7 & 84 & 81 & 23 & \\
\hline$\sigma_{\mu^{x}}^{0}$ & 0 & 20 & 11 & 28 & 33 & 12 & 32 & 35 & 57 & \\
\hline$\sigma_{\mu^{x}}^{4}$ & 0 & 38 & 24 & 39 & 31 & 8 & 68 & 79 & 72 & \multirow{4}{*}{40} \\
\hline$\sigma_{\mu^{x}}^{8}$ & 0 & 39 & 24 & 40 & 31 & 10 & 68 & 76 & 61 & \\
\hline$\sigma_{\mu}^{0}$ & 0 & 15 & 13 & 69 & 11 & 4 & 42 & 57 & 96 & \\
\hline$\sigma_{\mu}^{4}$ & 0 & 43 & 33 & 74 & 37 & 5 & 82 & 80 & 40 & \\
\hline$\sigma_{\mu}^{8}$ & 0 & 45 & 33 & 66 & 39 & 6 & 83 & 81 & 34 & \multirow{4}{*}{20} \\
\hline$\sigma_{\zeta}^{0}$ & 0 & 25 & 3 & 5 & 3 & 1 & 21 & 44 & 85 & \\
\hline$\sigma_{\zeta}^{4}$ & 0 & 67 & 34 & 68 & 44 & 6 & 85 & 84 & 16 & \\
\hline$\sigma_{\zeta}^{8}$ & 0 & 66 & 32 & 66 & 43 & 6 & 84 & 82 & 20 & \\
\hline$\sigma_{z^{I}}^{0}$ & 0 & 60 & 74 & 84 & 54 & 23 & 92 & 77 & 10 & \multirow{3}{*}{0} \\
\hline$\sigma_{z^{I}}^{4}$ & 0 & 76 & 56 & 93 & 69 & 31 & 90 & 77 & 43 & \\
\hline$\sigma_{z^{I}}^{8}$ & 0 & 70 & 58 & 90 & 65 & 40 & 85 & 71 & 35 & \\
\hline & $y$ & $c$ & $i$ & $h$ & $g$ & $a$ & $t f p$ & $v^{f}$ & $r$ & \\
\hline
\end{tabular}

Figure 2: Efficiency gains at MLE of SGU. 
Redundancy of output. An interesting result that emerged from the above analysis is that output growth data does not contribute any additional information with respect to either latent variables (i.e. innovations and shocks) or the free parameters in the model. In other words $y$ is redundant given the other observed variables. In fact, it can be shown that, as long as the growth rates of consumption, investment and government expenditures are observed, the output growth variable is only informative with respect to one parameter - the standard deviation of the measurement error $\sigma_{g^{y}}^{m e}$. Two assumptions in SGU are responsible for this result: (1) several model parameters are known, and (2) output is the only variable observed with measurement error. Relaxing either one of these assumptions would make output growth informative. For more details, see Iskrev (2015).

To summarize, the analysis in this section shows that the two asset price variables in the SGU model are not particularly informative about either the realizations of news shocks or parameters related to news shocks. Macroeconomic aggregates, such as hours worked, TFP, or the relative price of investment, are about as informative with respect to news shocks as are the value of the firm (stock prices) or the risk-free interest rate. Needless to say, this is a conclusion about the properties of the estimated SGU model. Making any changes that affect the way news shocks propagate throughout the economy could alter the results. In particular, different values of the structural parameters could imply a much larger information content of asset prices. As already mentioned, using the median of the posterior distribution reported in SGU does not change the main conclusions regarding the informativeness of $v^{f}$ and $r$. This can be seen in Figure A.5 in the Appendix, which shows conditional information gains for all variables at the posterior median. In addition, Figures A.6 and A.7 do the same for two other parameterizations of the SGU model (see also Table A.3). The first one comes from Herbst and Schorfheide (2014) who estimate the same model with the same set of observables as SGU using a different (and arguably superior) estimation approach. The second one is from Miyamoto and Nguyen (2015) who estimate the same model using, in 
addition to the variables in SGU, also forecasts of one to four quarters ahead output growth rates. As can be seen in the figures, overall the results imply even smaller information gains with respect to news shocks due to $v^{f}$ and $r$.

\subsection{Avdjiev (2016) model}

The second model I consider is taken from Avdjiev (2016). It is also a real business cycle model sharing many of the features of the SGU model. A brief summary of these features is provided below.

The representative agent maximizes the following utility function:

$$
\mathrm{E}_{0} \sum_{t=0}^{\infty} \beta^{t} \frac{\left[\left(C_{t}-\theta_{c} C_{t-1}\right)\left(l_{t}-\theta_{l} l_{t-1}\right)^{\chi}\right]^{1-\gamma}-1}{1-\gamma}
$$

where $C_{t}$ is consumption, $l_{t}$ is leisure, $\beta$ is the discount factor, $\gamma$ is the inverse of the intertemporal elasticity of substitution, $\chi$ determines the Frisch elasticity of labor supply, $\theta_{c}$ and $\theta_{l}$ are parameters determining the degrees of habit persistence in consumption and leisure, respectively. Output is produced using:

$$
Y_{t}=Z_{t}\left(u_{t} K_{t}\right)^{\alpha}\left(X_{t} h_{t}\right)^{1-\alpha},
$$

where $K_{t}$ is the existing capital stock, $h_{t}=1-l_{t}$ is hours worked, $u_{t}$ is the rate of capacity utilization, $Z_{t}$ is a stationary neutral productivity shock, and $X_{t}$ is a non-stationary neutral productivity shock.

The law of motion for the stock of capital is:

$$
K_{t+1}=\left(1-\delta\left(u_{t}\right)\right) K_{t}+\Omega_{t}\left[I_{t}-\frac{1}{2 \delta_{0} \eta}\left(\frac{I_{t}}{K_{t}}-\tau\right)^{2} K_{t}\right] \text {, }
$$

where $I_{t}$ is investment, $\delta$ is the rate of depreciation and is an increasing function of the rate of capacity utilization, $\Omega_{t}$ is a stationary investment-specific productivity shock, $\tau$ is the steady-state level of the investment-capital ratio, $\eta$ is the elasticity of the investment-capital ratio with respect to Tobin's $q$, and $\delta_{0}$ is the steady-state capital depreciation rate. 
There is no government in this economy and output is used for either consumption or investment:

$$
Y_{t}=C_{t}+I_{t} A_{t}
$$

where $A_{t}$ is a non-stationary investment specific productivity shock.

The main departure from the SGU model is in the way news shocks are introduced into the model. In particular, the specification of shock precesses in (3.6) is replaced with

$$
\begin{aligned}
& \ln \left(x_{t} / x\right)=\rho_{x}^{l} \ln \left(x_{t-1} / x\right)+\left(1-\rho_{x}^{l}\right) \ln \left(x_{t-1}^{L R}\right)+\sigma_{x, u} \varepsilon_{x, t}^{u} \\
& \ln \left(x_{t}^{L R}\right)=\rho_{x}^{L R} \ln \left(x_{t-1}^{L R}\right)+\sigma_{x, L R} \varepsilon_{x, t}^{L R},
\end{aligned}
$$

where $\varepsilon_{x}^{u}$ and $\varepsilon_{x}^{L R}$ are independent standard normal random variables. Avdjiev (2016) further assumes that $0<\rho_{x}^{l}<1$ and $\rho_{x}^{L R}=0.999$, which implies that $\ln \left(x_{t}^{L R}\right)$ can be interpreted as the long-run component of $\ln \left(x_{t} / x\right) .{ }^{16}$ Therefore, $\varepsilon_{x}^{L R}$ is the anticipated change in the long-run value of the shock. The model contains only four of the seven fundamental shocks present in the SGU model, namely: stationary and non-stationary neutral productivity shocks and stationary and non-stationary investment-specific productivity shocks. All shocks evolve as in (3.14), implying that there are four different long-run components and eight exogenous innovations, four of which are interpreted as long run (LR) news shocks.

Avdjiev (2016) argues that the long-run specification of news shocks fits the data better than the specification in (3.6). Importantly, Avdjiev (2016) uses asset price data to estimate the model. The two asset price variables used are the growth rate of the total stock market valuation and the real risk-free rate. These variables are assumed to be noisy measures of $v^{f}$ and $r$, which are defined as in section 3.1. In addition, five macroeconomic variables are used in the estimation: the growth rates of output $\left(y_{t}\right)$, consumption $\left(c_{t}\right)$, and investment $\left(i_{t}\right)$, hours worked $\left(h_{t}\right)$, and the relative price of investment $\left(a_{t}\right)$.

16. Note that if $\rho_{x}^{L R}=1$ then $\lim _{s \rightarrow \infty} \mathrm{E}_{t} \ln \left(x_{t+s} / x\right)=\ln \left(x^{L R}\right)$. 


\begin{tabular}{|c|c|c|c|c|c|c|c|}
\hline & innovation & $\operatorname{IG}(\bar{y})$ & $\mathrm{IG}\left(v^{f}, r \mid \overline{\boldsymbol{y}}\right)$ & $\mathrm{IG}\left(v^{f} \mid \overline{\boldsymbol{y}}\right)$ & $\mathrm{IG}(r \mid \overline{\boldsymbol{y}})$ & $\operatorname{IG}\left(v^{f}\right)$ & $\mathrm{IG}(r)$ \\
\hline$\varepsilon_{x}^{u}$ & non-stat. neutral prod. & 92.4 & 5.4 & 0.1 & 5.4 & 3.3 & 0.3 \\
\hline$\varepsilon_{x}^{L R}$ & non-stat. neutral prod. LR news & 0.2 & 0.2 & 0.1 & 0.1 & 0.1 & 0.0 \\
\hline$\varepsilon_{a}^{u}$ & non-stat. investment-specific prod. & 99.5 & 0.4 & 0.3 & 0.0 & 1.7 & 0.8 \\
\hline$\varepsilon_{a}^{L R}$ & non-stat. investment-specific prod. LR news & 42.8 & 44.7 & 36.9 & 3.6 & 60.5 & 1.8 \\
\hline$\varepsilon_{z}^{u}$ & stat. neutral prod. & 94.8 & 4.0 & 0.4 & 3.8 & 1.8 & 52.7 \\
\hline$\varepsilon_{z}^{L R R}$ & stat. neutral prod. LR news & 37.2 & 48.0 & 9.5 & 43.0 & 12.4 & 31.8 \\
\hline$\varepsilon_{\omega}^{u}$ & stat. investment-specific prod. & 57.8 & 35.4 & 35.3 & 1.1 & 7.5 & 3.7 \\
\hline$\varepsilon_{\omega}^{L R}$ & stat. investment-specific prod. LR news & 0.0 & 0.0 & 0.0 & 0.0 & 0.0 & 0.0 \\
\hline
\end{tabular}

Note: see the note to Table 1. $\bar{y}$ includes the growth rates of output, consumption, and investment, hours worked, and the relative price of investment.

TABLE 4. Information content of asset prices: innovations

3.2.1. Information about news shocks. I proceed along the lines of the analysis carried out in section Section 3.1.1. Note that now $\boldsymbol{y}$ is a $T \times 7$ dimensional vector, and $\overline{\boldsymbol{y}}=\boldsymbol{y} \backslash\left(v^{f}, r\right)$ is a $T \times 5$ dimensional vector. I set $T=236$, which is the sample size in Avdjiev (2016), and assume that $\boldsymbol{\theta}$ is equal to the median of the posterior distribution reported in Avdjiev (2016) (see Table A.4 in the Appendix).

The results are presented in Table 4. Including asset prices among the observables leads to significant information gains with respect to two of the news shocks - the anticipated innovations in the non-stationary investmentspecific productivity shock $\varepsilon_{a}^{L R}$, and the stationary neutral productivity shock $\varepsilon_{z}^{L R}$. Almost all of the gains in the first case are due to including $v^{f}$, while in the second most of the information is contributed by $r$. However, neither one of the innovations can be fully recovered from $\boldsymbol{y}$. The total information gains are around $88 \%$ for $\varepsilon_{a}^{L R}$ and $85 \%$ for $\varepsilon_{z}^{L R}$. The respective unconditional gains reported in the last two columns are relatively large, implying that, in contrast to the SGU model, $v^{f}$ and $r$ contribute significant amounts of nonredundant information with respect to $\varepsilon_{a}^{L R}$ and $\varepsilon_{z}^{L R}$. There is essentially no information in the set of observables as a whole about the news components of the other two shocks - the non-stationary neutral productivity shock and the stationary investment-specific productivity shock. This can be understood from the observation that the standard deviations of these innovations are estimated to be very small compared to the standard deviations of the unanticipated 
innovations to the same shocks. ${ }^{17}$ Furthermore, since the stationary investmentspecific productivity shock is estimated to be very persistent, the coefficient on the long-run component in (3.14) is close to zero, making $\varepsilon_{\omega}^{L R}$ very difficult to identify.

In addition to the two news shocks components, asset prices, and in particular $v^{f}$, contribute a significant amount of information with respect to the unanticipated innovations to the stationary investment specific productivity shock $\varepsilon_{\omega}^{u}$. The small size of the unconditional gain implies that the contribution of $v^{f}$ is largely a result of the interactions of that variable with variables in $\overline{\boldsymbol{y}}$.

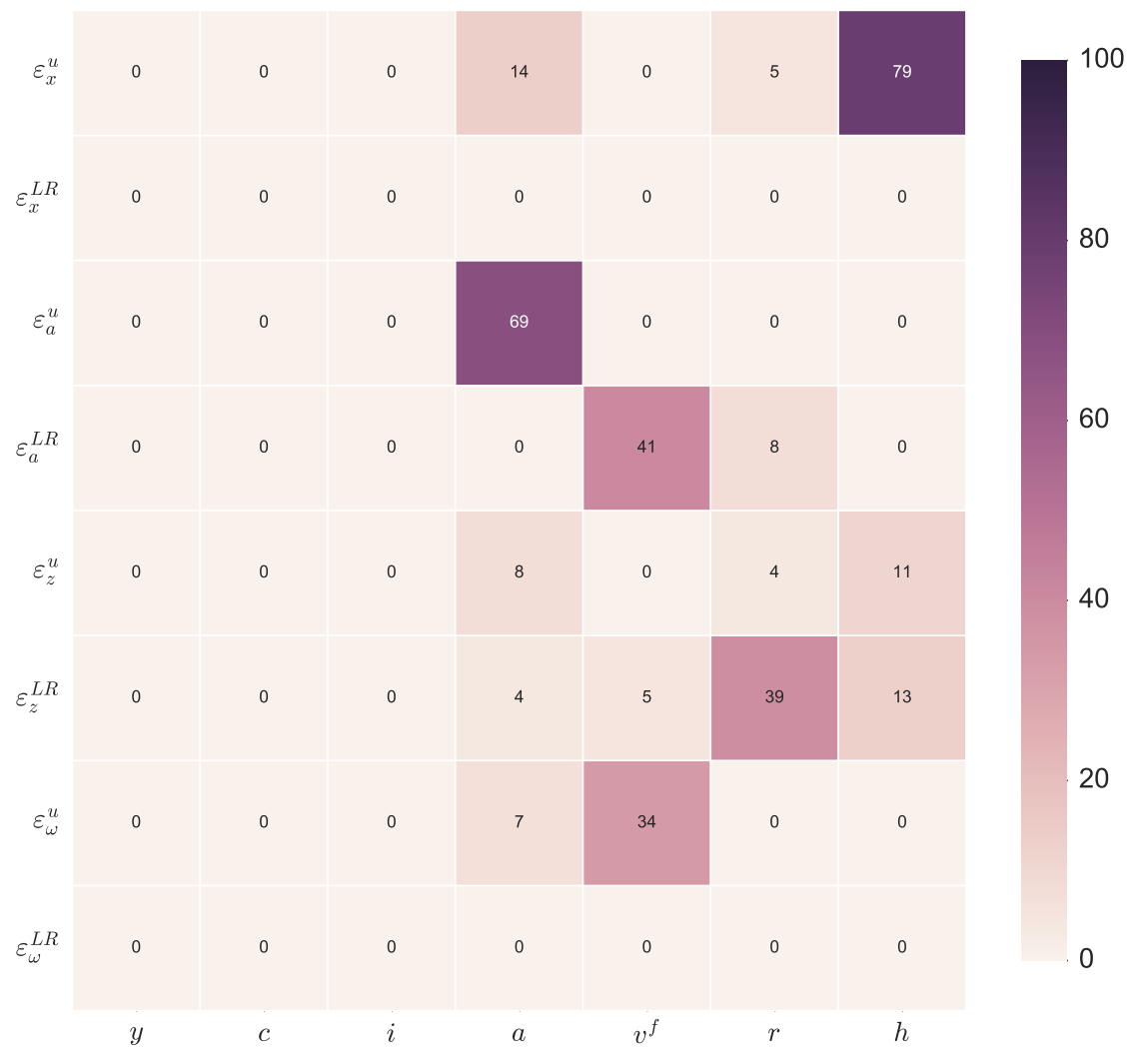

Figure 3: Conditional information gains in the model of Avdjiev (2016).

17. The posterior median estimates are: $\sigma_{x}^{L R}=0.01$ vs. $\sigma_{x}^{u}=1.05$ and $\sigma_{\omega}^{L R}=0.07$ vs. $\sigma_{\omega}^{u}=9.97$. 
To find out how the contributions of $v^{f}$ and $r$ compare to other variable, Figure 3 presents conditional information gains for each one of the seven observables. The results show that $v^{f}$ and $r$ are indeed the most informative variables with respect to the two identified news shocks. In the case of $\varepsilon_{z}^{L R}$, the conditional information gain from observing hours worked is somewhat larger than the gain from including $v^{f}$, but is smaller than the information gain from observing $r$. The relative price of investment is the only other observable with a positive marginal contribution. None of the macro variables makes a positive contribution with respect to $\varepsilon_{a}^{L R}$. Note that, as in section 3.1, the gains from each variable are conditional on information contained in the remaining six variables. This is why the results for $v^{f}$ and $r$ are different from the values in Table 4 (columns 3 and 4). In particular, the information gains with respect to $\varepsilon_{a}^{L R}$ due to either $v^{f}$ or $r$ are larger when the conditioning set includes the other asset price variable compared to when it does not. This indicates a positive conditional information complementarity between $v^{f}$ and $r$ with respect to that shock. At the same time, there is a negative complementarity with respect to the news component in the stationary neutral productivity shock. ${ }^{18}$ Additional results from conditional and unconditional information complementarity analysis are presented in Figures A.8 - A.11 of the Appendix. There is a significant information complementarity between $v^{f}$ and $a$ with respect to the news components in two of the shocks - negative with respect to the stationary neutral productivity shock, and positive with respect to the stationary investment-specific productivity shock. There is also a positive complementarity between $v^{f}$ and $h$ with respect to the stationary neutral productivity shock. In the case of $r$, the only significant complementarity is with $a$-positive with respect to the news component in the non-stationary neutral productivity shock.

18. Another way to see this is by comparing the joint information gains to the sum of the individual gains in Table 4. 


\begin{tabular}{llrrrrrr}
\hline \multicolumn{1}{c}{ shock } & $\mathrm{IG}(\overline{\boldsymbol{y}})$ & $\mathrm{IG}\left(v^{f}, r \mid \overline{\boldsymbol{y}}\right)$ & $\mathrm{IG}\left(v^{f} \mid \overline{\boldsymbol{y}}\right)$ & $\mathrm{IG}(r \mid \overline{\boldsymbol{y}})$ & $\mathrm{IG}\left(v^{f}\right)$ & $\mathrm{IG}(r)$ \\
\hline$\mu_{x}$ & non-stat. neutral prod. & 93.3 & 4.9 & 0.1 & 4.9 & 3.3 & 0.4 \\
$\mu_{x}^{L R}$ & non-stat. neutral prod. LR comp. & 0.8 & 0.4 & 0.1 & 0.3 & 0.1 & 0.0 \\
$\mu_{a}$ & non-stat. investment-specific prod. & 100.0 & 0.0 & 0.0 & 0.0 & 5.2 & 3.5 \\
$\mu_{a}^{L R}$ & non-stat. investment-specific prod. LR comp. & 44.3 & 43.5 & 35.9 & 3.5 & 60.7 & 3.3 \\
$z$ & stat. neutral prod. & 95.9 & 3.0 & 0.8 & 2.5 & 4.6 & 63.1 \\
$z^{L R}$ & stat. neutral prod. LR comp. & 37.8 & 47.5 & 9.4 & 42.5 & 12.4 & 31.7 \\
$\omega$ & stat. investment-specific prod. & 57.7 & 35.3 & 35.3 & 1.1 & 7.5 & 3.7 \\
$\omega^{L R}$ & stat. investment-specific prod. LR comp. & 0.0 & 0.0 & 0.0 & 0.0 & 0.0 & 0.0 \\
\hline
\end{tabular}

Note: see note to Table 1.

TABLE 5. Information content of asset prices: shocks

Another interesting result in Figure 3 is the apparent lack of information in $y, i$ and $c$. In fact, the conditional information gains are positive but very small, suggesting near redundancy of these variables. This is easily explained by the observation that the economy's resource constraint (see equation (3.13)) implies linear dependence among $y, i$ and $c .{ }^{19}$ Stochastic singularity is avoided by assuming measurement errors in all variables. However, the size of the errors in $y, i$ and $c$ is very small, implying that any one of them is (nearly) redundant given the other two.

Table 5 reports results on the information content of asset prices with respect to the four structural shocks and their long-run components. The information gains are very similar to the ones with respect to the innovations, presented in Table 4, both in terms of the size of the gains and the contribution of each asset prices variable. This is to be expected given that shocks and innovations are closely linked to each other in this model.

3.2.2. Information about parameters. Table 6 reports parameter efficiency gains due to observing the two asset price variables. The gains with respect to the standard deviations of the four news shocks are between $25 \%$ and $86 \%$. Similar to the information gains results in Table $4, v^{f}$ is relatively more informative for the parameters of the two investment-specific productivity shocks, while $r$ is more informative about the parameters of the stationary

19. As in the SGU model, the observed investment series is defined as $i_{t}:=\triangle \ln A_{t} I_{t}$. 


\begin{tabular}{|c|c|c|c|c|}
\hline & parameter & $v^{f}, r$ & $v^{f}$ & $r$ \\
\hline$\gamma$ & inverse intertemporal elasticity of substitution & 18 & 1 & 16 \\
\hline$\chi$ & Frisch elasticity of labor supply & 99 & 44 & 98 \\
\hline$\theta_{l}$ & habit in leisure, & 40 & 14 & 37 \\
\hline$\theta_{c}$ & habit in consumption, & 36 & 10 & 26 \\
\hline$\delta_{2}$ & capacity utilization cost & 88 & 83 & 26 \\
\hline$\eta$ & investment adjustment cost & 88 & 85 & 21 \\
\hline$\rho_{x}^{l}$ & AR non-stationary neutral productivity & 85 & 1 & 85 \\
\hline$\rho_{a}^{l}$ & AR non-stationary investment-specific productivity & 19 & 13 & 10 \\
\hline$\rho_{z}^{l}$ & AR stationary neutral productivity & 90 & 17 & 88 \\
\hline$\rho_{\omega}^{l}$ & AR stationary investment-specific productivity & 52 & 47 & 15 \\
\hline$\sigma_{x, u}$ & std. non-stationary neutral productivity & 33 & 5 & 31 \\
\hline$\sigma_{x, L R}$ & std. non-stationary neutral productivity LR news & 25 & 1 & 25 \\
\hline$\sigma_{a, u}$ & std. non-stationary investment-specific productivity & 5 & 4 & 1 \\
\hline$\sigma_{a, L R}$ & std. non-stationary investment-specific productivity LR news & 69 & 54 & 17 \\
\hline$\sigma_{z, u}$ & std. stationary neutral productivity & 45 & 13 & 45 \\
\hline$\sigma_{z, L R}$ & std. stationary neutral productivity LR news & 64 & 24 & 50 \\
\hline$\sigma_{\omega, u}$ & std. stationary investment-specific productivity & 90 & 89 & 18 \\
\hline$\sigma_{\omega, L R}$ & std. stationary investment-specific productivity LR news & 86 & 86 & 10 \\
\hline
\end{tabular}

Note: see note to Table 3 .

TABLE 6. Efficiency gains (\%)

and non-stationary neutral productivity shocks. Notice that this applies to all parameters of the same shock, including the autoregressive coefficients and the standard deviations of the unanticipated shocks.

It is worth pointing out that the news shock parameters, and in particular $\sigma_{x, L R}$ and $\sigma_{\omega, L R}$, are identified, in spite of the earlier finding that there is very little information about the realizations of the news components of the nonstationary neutral productivity and stationary investment-specific productivity shocks. Lack of identification would imply an infinite value of the CRLB. As can be seen in Table A.5 in the Appendix, which shows the CRLBs with and without asset prices, they are all finite. The values for $\sigma_{\omega, L R}$, however, are very large, suggesting that the likelihood surface is in fact very flat with respect to that parameter. Two other parameters with extremely large values of the CRLB are the cost of capacity utilization parameter $\delta_{2}$ and the Frisch elasticity of labor supply $\chi$. Notice that, even though the values of the CRLBs of $\sigma_{\omega, L R}$ an $\delta_{2}$ are almost equal, the levels of uncertainty they imply are very different since $\delta_{2}=3.91$ while $\sigma_{\omega, L R}=0.07$. 
To find out how $v^{f}$ and $r$ compare to other observables, Figure 4 shows the efficiency gains due to each one of the seven variables. Only with respect to one of the news shock parameters - the standard deviation of the long-run news component in the non-stationary investment specific-productivity shock $\left(\sigma_{a, L R}\right)$, is $v^{f}$ significantly more informative than any other variable. The relative price of investment is about as informative as $v^{f}$ with resect to the standard deviation of the long-run news component in the stationary investment-specific productivity shock $\left(\sigma_{\omega, L R}\right)$, and is also by far the most informative variable with respect to the standard deviation of the long-run news component in the non-stationary neutral productivity shock $\left(\sigma_{x, L R}\right)$. Lastly, hours worked is the most informative variable with respect to the standard deviation of the long-run news component in the stationary neutral productivity shock $\left(\sigma_{z, L R}\right)$.

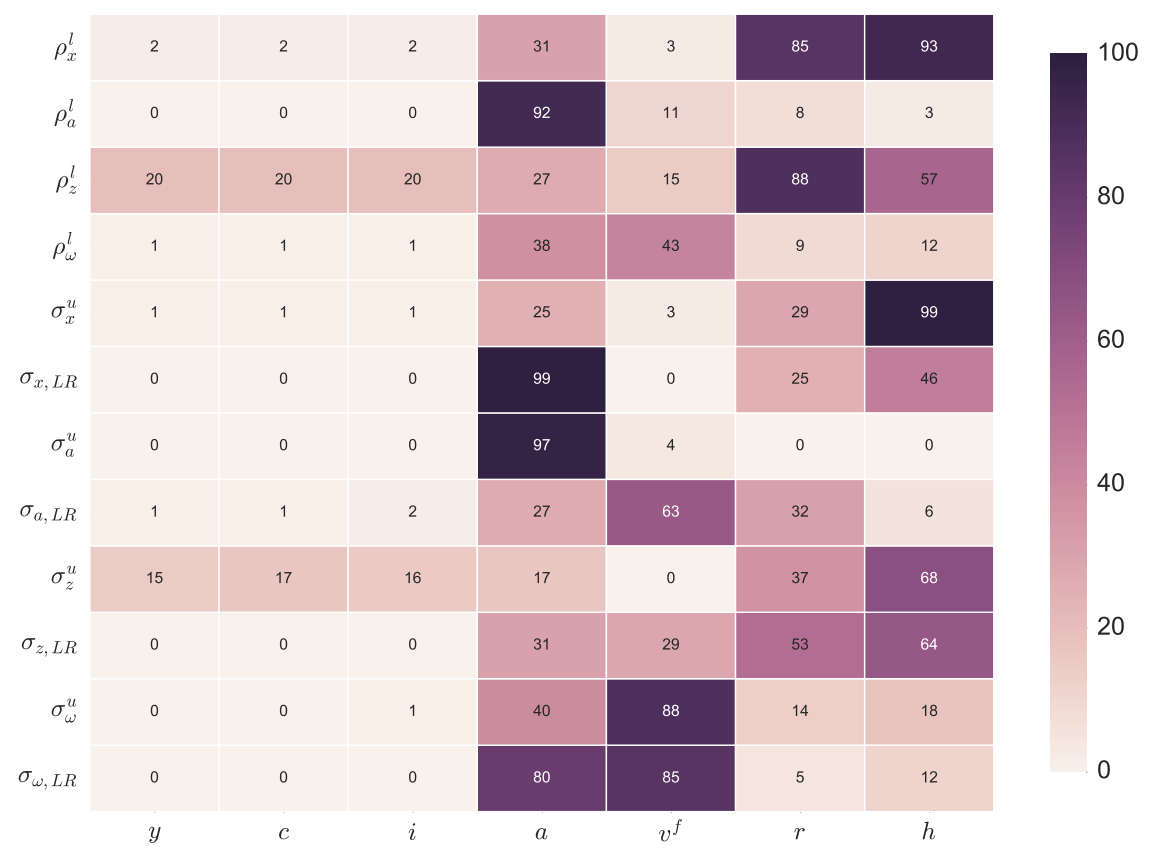

Figure 4: Efficiency gains in the model of Avdjiev (2016).

It should be noted that the these results are obtained under the assumption that the standard deviations of the measurement errors are known. Without 


\begin{tabular}{|c|c|c|c|c|c|c|c|}
\hline & innovation & $\mathrm{IG}(\overline{\boldsymbol{y}})$ & $\mathrm{IG}\left(v^{f}, r \mid \overline{\boldsymbol{y}}\right)$ & $\mathrm{IG}\left(v^{f} \mid \overline{\boldsymbol{y}}\right)$ & $\mathrm{IG}(r \mid \overline{\boldsymbol{y}})$ & $\mathrm{IG}\left(v^{f}\right)$ & $\mathrm{IG}(r)$ \\
\hline$\varepsilon_{x}^{u}$ & non-stat. neutral prod. & 92.6 & 5.4 & 0.2 & 5.4 & 3.3 & 0.3 \\
\hline$\varepsilon_{x}^{L R}$ & non-stat. neutral prod. LR news & 0.3 & 0.1 & 0.0 & 0.1 & 0.1 & 0.0 \\
\hline$\varepsilon_{a}^{u}$ & non-stat. investment-specific prod. & 99.8 & 0.1 & 0.1 & 0.1 & 1.7 & 0.8 \\
\hline$\varepsilon_{a}^{L R}$ & non-stat. investment-specific prod. LR news & 78.8 & 15.0 & 6.4 & 10.0 & 60.5 & 1.8 \\
\hline$\varepsilon_{z}^{u}$ & stat. neutral prod. & 95.5 & 3.4 & 0.1 & 3.4 & 1.8 & 52.7 \\
\hline$\varepsilon_{z}^{\tilde{L} R}$ & stat. neutral prod. LR news & 48.0 & 40.1 & 1.8 & 39.7 & 12.4 & 31.8 \\
\hline$\varepsilon_{\omega}^{u}$ & stat. investment-specific prod. & 93.8 & 3.6 & 3.6 & 0.1 & 7.5 & 3.7 \\
\hline$\varepsilon_{\omega}^{L R}$ & stat. investment-specific prod. LR news & 0.0 & 0.0 & 0.0 & 0.0 & 0.0 & 0.0 \\
\hline
\end{tabular}

Note: see the note to Table 1. $\bar{y}$ includes the growth rates of output, consumption, investment, and $T F P$, hours worked, and the relative price of investment.

TABLE 7. Information content of asset prices: innovations

it the efficiency gains cannot be computed since the measurement error parameters are not identified unless the respective variables are observed. This does not affect the conclusions regarding the contributions of asset prices, but does inflate the efficiency gains with respect to $\rho_{z}^{l}$ and $\sigma_{z, u}$ due to $y, c$, and $i .^{20}$

The role of TFP.. The results in this section suggest a much greater and more distinct role of asset prices with respect to news shocks in the model of Avdjiev (2016) compared to the SGU model. In particular, $v^{f}$ and $r$ are found to be considerably more informative than any other observed variable with respect to two of the news shocks - the long-run news components of the non-stationary investment-specific productivity shock $\left(\varepsilon_{a}^{L R}\right)$ and the stationary neutral productivity shock $\left(\varepsilon_{z}^{L R}\right)$. One possible explanation of this finding is that TFP growth is assumed to be observed in the analysis of the SGU model but not for the model in this section. Since that variable was found to be quite informative with respect to several anticipated innovations in the SGU model, it is possible that the contribution of $v^{f}$ and $r$ in the model of Avdjiev (2016) is exaggerated by its exclusion. To examine this possibility, Table 7 reevaluates the information content of asset prices assuming that $\overline{\boldsymbol{y}}$ contains $t f p$ in addition to the other five macro variables. The only major change

20. There are also relatively large and approximately equal efficiency gains with respect to the inverse intertemporal elasticity of substitution $\gamma$ and the habit in consumption $\theta_{c}$ due to $y, c$, and $i$. 
compared to Table 4 is with respect to the long-run news component in the nonstationary investment-specific productivity shock $\left(\varepsilon_{a}^{L R}\right)$ and the unanticipated innovation to the stationary investment-specific productivity shock $\left(\varepsilon_{\omega}^{u}\right)$. In both cases the conditional contribution of information by asset prices is much smaller when $\overline{\boldsymbol{y}}$ includes $t f p$. Furthermore, the reduction is almost entirely due to the much smaller contribution of $v^{f}$. In the case of $\varepsilon_{a}^{L R}$ the conditional information gain of $v^{f}$ decreases from $37 \%$ to $15 \%$, while at the same time the information gain of $r$ increases from $3.6 \%$ to $10 \%$. This implies that there is a negative conditional complementarity between $v^{f}$ and $t f p$, and a positive conditional complementarity between $r$ and $t f p$ with respect to $\varepsilon_{a}^{L R}$. The same type of complementarity between asset prices and $t f p$ is found with respect to the stationary neutral productivity shock $\left(\varepsilon_{z}^{L R}\right)$. However, since the relative contribution of $v^{f}$ is much smaller, the overall information gain of asset prices with respect to that shock remains large.

Figure 5 presents the conditional information gains of all eight variables. $r$ is slightly more informative than $t f p, h, v^{f}$ and $a$ with respect to $\varepsilon_{a}^{L R}$; it is, however, by far the most informative variable with respect to $\varepsilon_{a}^{L R}$. Comparing the results against those presented in Figure 3 shows that the inclusion of $t f p$ has also a significant impact on the contribution of information by $h$ and $a$. For instance, the conditional gain of $h$ with respect to the non-stationary neutral productivity shock $\left(\varepsilon_{x}^{u}\right)$ declines from $80 \%$ when $t f p$ is excluded from $\overline{\boldsymbol{y}}$ to $1 \%$ when it is included. This means that, conditional on the other observables, $h$ and $t f p$ are close substitutes in terms of information they contribute about $\varepsilon_{x}^{u}$. Similarly, there is a strong negative complementarity between $t f p$ and $a$ with respect to the non-stationary investment-specific productivity shock $\left(\varepsilon_{a}^{u}\right)$.

The consequences, in terms of efficiency gains, of adding tfp as an observable are very similar: the contribution of $v^{f}$ is much smaller than before with respect to most parameters including $\sigma_{a, L R}$, for which it is the most informative variable when $t f p$ is unobserved. The relative importance of $r$, on the other hand, generally increases, and it becomes the variable with the 


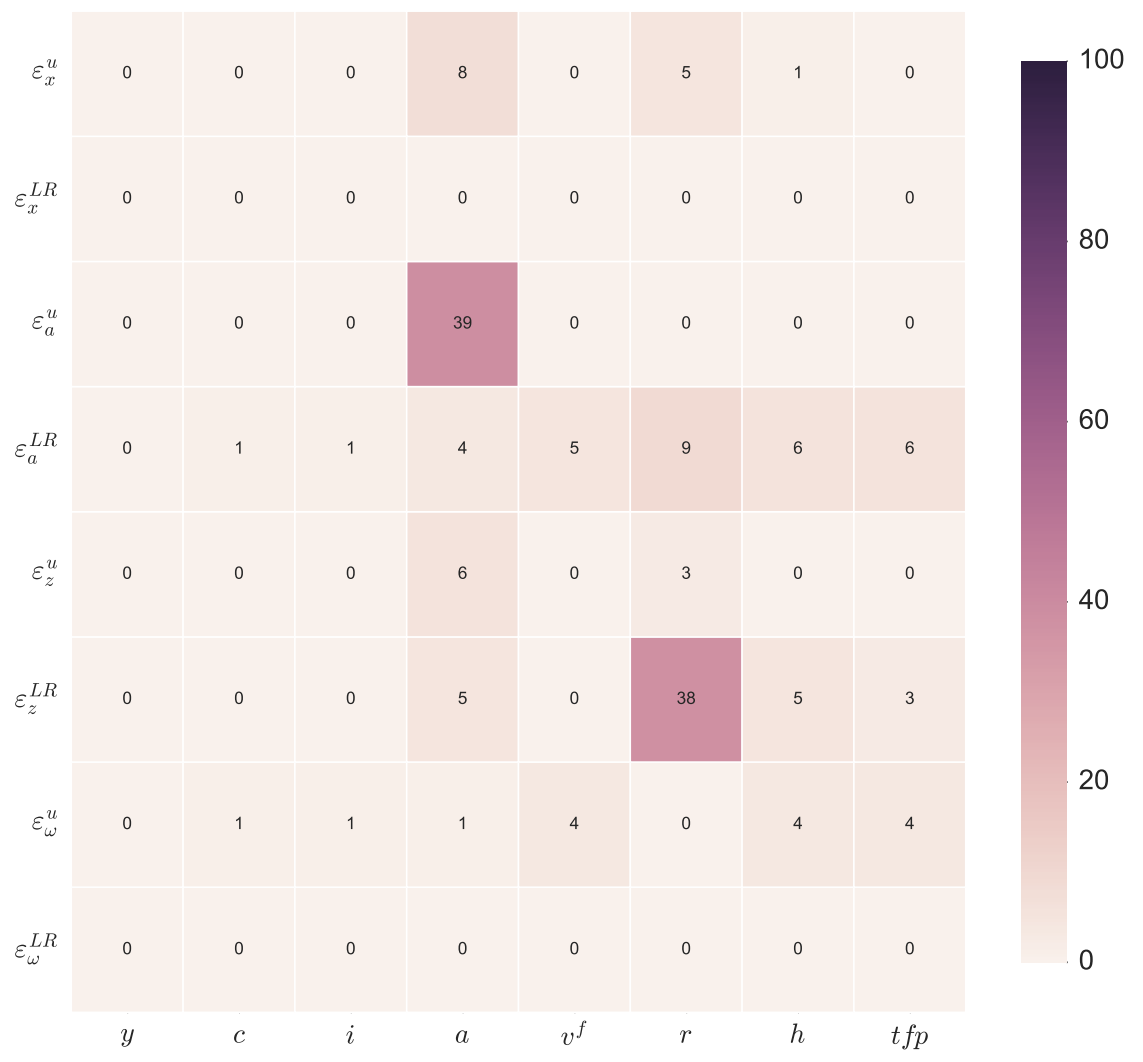

Figure 5: Conditional information gains in the model of Avdjiev (2016) when $t f p$ is observed.

largest contribution with respect to $\sigma_{z, L R}$. A complete set of results can be seen in Figure A.12 of the Appendix.

To summarize, when $t f p$ is among the observed variables, of the two asset prices only $r$ contributes significantly more information about one of the news shocks than any other observable. As in in section 3.1, that shock is the stationary neutral productivity news shock. Due to the relatively smaller number of shocks in the Avdjiev (2016) model, however, the information gained from observing $r$ is substantially larger than in the SGU model. 


\section{Conclusion}

The informational importance of observed variables with respect to shocks in business cycle models is often asserted without formal justification. This paper has proposed a general framework for evaluating the contribution of information that different variables make with respect to specific shocks. An application to two examples of DSGE models containing news shocks revealed relatively modest contribution of information by asset prices. A necessary caveat to these results is that they are entirely conditional on the particular models considered. Making changes in the way shocks are introduced and propagate, or in the way asset prices are modeled is likely to have an impact on the conclusions regarding the informational value of different observables. Indeed, this is an example of one of the intended purposes of the analysis developed in this paper, namely, checking whether models are consistent with our intuition about how the real world works. Finding out that they are not provides useful directions for their improvement.

The analysis in this paper can be extended in several directions. With regards to news-driven DSGE models, it would be interesting to know whether observing expectations provides significantly more information than observing asset prices. In terms of the methodology itself, more research is needed on how to perform this type of analysis in non-linear and non-Gaussian models. In particular, the information gains measures are, in general, not available in closed form, and would have to be estimated using simulated data. 


\section{References}

Alessi, L., M. Barigozzi, AND M. CAPAsso (2011): "Non-Fundamentalness in Structural Econometric Models: A Review," International Statistical Review, 79, 16-47.

Amblard, P.-O. And O. J. Michel (2011): "On directed information theory and Granger causality graphs," Journal of computational neuroscience, 30, $7-16$.

Avdjiev, S. (2016): "News Driven Business Cycles and data on asset prices in estimated DSGE models," Review of Economic Dynamics, 20, 181-197.

Barnett, L., A. B. Barrett, And A. K. Seth (2009): "Granger causality and transfer entropy are equivalent for Gaussian variables," Physical review letters, 103, 238701.

Barsky, R. B., S. Basu, And K. Lee (2014): "Whither News Shocks?" Tech. rep., National Bureau of Economic Research.

BARsky, R. B. AND E. R. Sims (2011): "News shocks and business cycles," Journal of Monetary Economics, 58, 273 - 289.

Beaudry, P., P. Fève, A. Guay, And F. Portier (2015): "When is Nonfundamentalness in VARs a Real Problem? An Application to News Shocks," Tech. rep., National Bureau of Economic Research.

Beaudry, P. And F. Portier (2004): "An exploration into Pigou's theory of cycles," Journal of Monetary Economics, 51, 1183 - 1216.

(2006): "Stock Prices, News, and Economic Fluctuations," The American Economic Review, 96, pp. 1293-1307.

Blanchard, O. J., J.-P. L'Huillier, and G. Lorenzoni (2013): "News, noise, and fluctuations: An empirical exploration," The American Economic Review, 103, 3045-3070.

Canova, F., F. Ferroni, And C. Matthes (2014): "Choosing the variables to estimate singular DSGE models," Journal of Applied Econometrics, 29, 1099-1117.

Cover, T. M. and J. A. Thomas (2006): Elements of information theory, 2nd edition, John Wiley \& Sons.

DAVIS, J. (2007): "News and the term structure in general equilibrium," Working papers, Northwestern University.

Dempster, A. P., N. M. Laird, And D. B. Rubin (1977): "Maximum likelihood from incomplete data via the EM algorithm," Journal of the royal statistical society. Series B, 1-38.

Fernandez-Villaverde, J., J. Rubio-Ramirez, T. J. Sargent, and M. W. WATson (2007): "A, B, Cs (and Ds) of Understanding VARs," American Economic Review, 97.

Forni, M. AND L. GAmBetTi (2014): "Sufficient information in structural VARs," Journal of Monetary Economics, 66, 124-136.

Franchi, M. AND P. PARUOLO (2015): "Minimality of state space solutions of DSGE models and existence conditions for their VAR representation," 
Computational Economics, 46, 613-626.

FrAnchi, M. AND A. VidotTo (2013): "A check for finite order VAR representations of DSGE models," Economics Letters, 120, 100-103.

GEWEKE, J. (1982): "Measurement of linear dependence and feedback between multiple time series," Journal of the American statistical association, 77, 304313.

GEwEKe, J. F. (1984): "Measures of conditional linear dependence and feedback between time series," Journal of the American Statistical Association, 79, 907-915.

GIACOMIni, R. (2013): "The relationship between DSGE and VAR models," Advances in Econometrics, 31.

Giannone, D. And L. Reichlin (2006): "Does information help recovering structural shocks from past observations?" Journal of the European Economic Association, 4, 455-465.

GörTZ, C. AND J. D. Tsoukalas (2016): "News and financial intermediation in aggregate fluctuations," Review of Economics and Statistics, forthcoming.

Granger, C. AND J.-L. LiN (1994): "Using the mutual information coefficient to identify lags in nonlinear models," Journal of time series analysis, 15, 371384.

Granger, C. W. (1969): "Investigating causal relations by econometric models and cross-spectral methods," Econometrica: Journal of the Econometric Society, 424-438.

Hansen, H. And T. Sargent (1991): "Two Difficulties in Interpreting Vector Autoregressions," in Rational Expectations Econometrics, ed. by H. Hansen and T. Sargent, Westview Press.

Hansen, L. P. And T. J. Sargent (1980): "Formulating and estimating dynamic linear rational expectations models," Journal of Economic Dynamics and control, 2, 7-46.

Herbst, E. ANd F. Schorfheide (2014): "Sequential Monte Carlo sampling for DSGE models," Journal of Applied Econometrics, 29, 1073-1098.

Hirose, Y. AND T. Kurozumi (2012): "Identifying News Shocks with Forecast Data," CAMA Working Papers 2012-01, Centre for Applied Macroeconomic Analysis, Crawford School of Public Policy, The Australian National University.

IsKREV, N. (2010): "Evaluating the strength of identification in DSGE models. An a priori approach," Working paper series, Banco de Portugal.

(2015): "What's News in Business Cycles? A Comment," Tech. rep.

IskREV, N. AND J. RitTo (2016): "Choosing the variables to estimate singular DSGE models: Comment," Tech. rep.

Jaimovich, N. And S. Rebelo (2009): "Can News about the Future Drive the Business Cycle?" American Economic Review, 99, 1097-1118.

JAROCiŃSKI, M. AND B. MAĆKOWIAK (2017): "Granger causal priority and choice of variables in vector autoregressions," Review of Economics and Statistics, 99, 319-329. 
Joe, H. (1989): "Relative entropy measures of multivariate dependence," Journal of the American Statistical Association, 84, 157-164.

KruskaL, W. (1987): "Relative Importance by Averaging Over Orderings," The American Statistician, 41, 6-10.

Kurmann, A. And C. OTRoK (2013): "News shocks and the slope of the term structure of interest rates," The American Economic Review, 103, 2612-2632.

LEePER, E. M., T. B. WALKER, AND S.-C. S. YANG (2013): "Fiscal foresight and information flows," Econometrica, 81, 1115-1145.

LiPPI, M. AND L. REICHLIN (1993): "The dynamic effects of aggregate demand and supply disturbances: Comment," The American Economic Review, 83, 644-652.

(1994): "VAR analysis, nonfundamental representations, Blaschke matrices," Journal of Econometrics, 63, 307-325.

Malkhozov, A. AND A. TAmoni (2015): "News shocks and asset prices," LSE Research Online Documents on Economics 62004, London School of Economics and Political Science, LSE Library.

Meng, X.-L. AND X. XIE (2014): "I got more data, my model is more refined, but my estimator is getting worse! Am I just dumb?" Econometric Reviews, $33,218-250$.

Milani, F. AND A. RAJBhandaRI (2012): "Observed expectations, news shocks, and the business cycle," University of California-Irvine Department of Economics Working Paper, 121305.

Miyamoto, W. and T. L. NGuyen (2015): "News shocks and Business cycles: Evidence from forecast data," Tech. rep.

Palm, F. C. And T. E. NiJman (1984): "Missing observations in the dynamic regression model," Econometrica: journal of the Econometric Society, 14151435.

PeÑA, D. AND A. V. D. Linde (2007): "Dimensionless measures of variability and dependence for multivariate continuous distributions," Communications in Statistics - Theory and Methods, 36, 1845-1854.

PEÑA, D. AND J. RodRÍGUEz (2003): "Descriptive measures of multivariate scatter and linear dependence," Journal of Multivariate Analysis, 85, 361 374.

Pourahmadi, M. And E. S. Soofi (2000): "Prediction variance and information worth of observations in time series," Journal of Time Series Analysis, 21, 413-434.

Pronzato, L. AND A. PÁzMAn (2013): "Design of experiments in nonlinear models," Lecture Notes in Statistics, 212.

RAO, C. R. (2002): Linear statistical inference and its applications, John Wiley \& Sons.

RAVENNA, F. (2007): "Vector autoregressions and reduced form representations of DSGE models," Journal of monetary economics, 54, 2048-2064.

Retzer, J. J., E. S. Soofi, AND R. Soyer (2009): "Information importance of predictors: Concept, measures, Bayesian inference, and applications," 
Computational Statistics \& Data Analysis, 53, 2363-2377.

SalA, L., L. Gambetti, M. Forni, et AL. (2016): "VAR Information and the Empirical Validation of DSGE Models," in 2016 Meeting Papers, Society for Economic Dynamics, 260.

Schmitt-Grohé, S. And M. URIBE (2012): "What's News in Business Cycles," Econometrica, 80, 2733-2764.

SCHREIBER, T. (2000): "Measuring information transfer," Physical review letters, 85, 461.

Shannon, C. E. (1948): "A mathematical theory of communication," Bell System Technical Journal, 27, 379-423.

SiLVEY, S. (1980): Optimal design: an introduction to the theory for parameter estimation, Chapman and Hall, London.

Sims, E. R. (2012): "News, non-invertibility, and structural VARs," Advances in Econometrics, 28, 81.

SoCCORsI, S. (2016): "Measuring nonfundamentalness for structural VARs," Journal of Economic Dynamics and Control, 71, 86-101.

Soofi, E. S. (1992): "A generalizable formulation of conditional logit with diagnostics," Journal of the American Statistical Association, 87, 812-816.

Theil, H. (1987): "How many bits of information does an independent variable yield in a multiple regression?" Statistics \& probability letters, 6, 107-108.

Theil, H. And C. Chung (1988): "Information-theoretic measures of fit for univariate and multivariate linear regressions," The American Statistician, 42, 249-252.

WEI, W. W. (1978a): "The effect of temporal aggregation on parameter estimation in distributed lag model," Journal of Econometrics, 8, 237-246.

(1978b): "Some consequences of temporal aggregation in seasonal time series models," in Seasonal analysis of economic time series, NBER, 433-448.

WiLKs, S. S. (1932): "Certain generalizations in the analysis of variance," Biometrika, 471-494. 


\section{Appendix:}

\section{A.1. Schmitt-Grohé and Uribe (2012) model}

\begin{tabular}{|c|c|c|c|}
\hline & parameter & MLE & posterior median \\
\hline$\theta$ & Frisch elasticity of labor supply & 5.39 & 4.74 \\
\hline$\gamma$ & wealth elasticity of labor supply & 0.00 & 0.00 \\
\hline$\kappa$ & investment adjustment cost & 25.07 & 9.11 \\
\hline$\delta_{2} / \delta_{1}$ & capacity utilization cost & 0.44 & 0.34 \\
\hline$b$ & habit in consumption & 0.94 & 0.91 \\
\hline$\rho_{x g}$ & government spending & 0.74 & 0.72 \\
\hline$\rho_{z}$ & AR stationary neutral productivity & 0.96 & 0.92 \\
\hline$\rho_{\mu^{a}}$ & AR non-stationary investment-specific productivity & 0.48 & 0.48 \\
\hline$\rho_{g}$ & AR government spending & 0.96 & 0.96 \\
\hline$\rho_{\mu^{x}}$ & AR non-stationary neutral productivity & 0.27 & 0.38 \\
\hline$\rho_{\mu}$ & AR wage markup & 0.98 & 0.98 \\
\hline$\rho_{\zeta}$ & AR preference & 0.10 & 0.17 \\
\hline$\rho_{z^{I}}$ & AR stationary investment-specific productivity & 0.21 & 0.47 \\
\hline$\sigma_{z}^{0}$ & std. stationary neutral productivity 0 & 0.62 & 0.65 \\
\hline$\sigma_{z}^{4}$ & std. stationary neutral productivity 4 & 0.11 & 0.11 \\
\hline$\sigma_{z}^{8}$ & std. stationary neutral productivity 8 & 0.11 & 0.09 \\
\hline$\sigma_{\mu}^{0}$ & std. non-stationary investment-specific productivity 0 & 0.16 & 0.21 \\
\hline$\sigma_{\mu^{a}}^{4}$ & std. non-stationary investment-specific productivity 4 & 0.20 & 0.16 \\
\hline$\sigma_{\mu}^{8}$ & std. non-stationary investment-specific productivity 8 & 0.19 & 0.16 \\
\hline$\sigma_{g}^{0}$ & std. government spending 0 & 0.53 & 0.62 \\
\hline$\sigma_{g}^{4}$ & std. government spending 4 & 0.69 & 0.57 \\
\hline$\sigma_{g}^{8}$ & std. government spending 8 & 0.43 & 0.37 \\
\hline$\sigma_{\mu^{x}}^{0}$ & std. non-stationary neutral productivity 0 & 0.45 & 0.38 \\
\hline$\sigma_{\mu^{x}}^{4}$ & std. non-stationary neutral productivity 4 & 0.12 & 0.08 \\
\hline$\sigma_{\mu^{x}}^{8}$ & std. non-stationary neutral productivity 8 & 0.12 & 0.10 \\
\hline$\sigma_{\mu}^{0}$ & std. wage markup 0 & 1.51 & 0.50 \\
\hline$\sigma_{\mu}^{4}$ & std. wage markup 4 & 3.93 & 4.79 \\
\hline$\sigma_{\mu}^{8}$ & std. wage markup 8 & 3.20 & 0.51 \\
\hline$\sigma_{\zeta}^{0}$ & std. preference 0 & 2.83 & 4.03 \\
\hline$\sigma_{\zeta}^{4}$ & std. preference 4 & 2.76 & 1.89 \\
\hline$\sigma_{\zeta}^{8}$ & std. preference 8 & 5.34 & 2.21 \\
\hline$\sigma_{z^{I}}^{0}$ & std. stationary investment-specific productivity 0 & 34.81 & 11.72 \\
\hline$\sigma_{z^{I}}^{4}$ & std. stationary investment-specific productivity 4 & 11.99 & 1.93 \\
\hline$\sigma_{z^{I}}^{8}$ & std. stationary investment-specific productivity 8 & 14.91 & 5.50 \\
\hline
\end{tabular}

Note: The values are taken from Table II of Schmitt-Grohé and Uribe (2012)

TABle A.1. Parameter values, SGU (2012) model 


\begin{tabular}{|c|c|c|c|}
\hline & parameter & $\bar{y}$ & $y$ \\
\hline$\theta$ & Frisch elasticity of labor supply & 1.65135 & 0.27551 \\
\hline$\gamma$ & wealth elasticity of labor supply & 0.00002 & 0.00001 \\
\hline$\kappa$ & investment adjustment cost & 30.63677 & 1.50300 \\
\hline$\delta_{2} / \delta_{1}$ & capacity utilization cost & 0.03112 & 0.00040 \\
\hline$b$ & habit in consumption & 0.00018 & 0.00004 \\
\hline$\rho_{x g}$ & government spending & 0.04158 & 0.02751 \\
\hline$\rho_{z}$ & AR stationary neutral productivity & 0.00178 & 0.00026 \\
\hline$\rho_{\mu^{a}}$ & AR non-stationary investment-specific productivity & 0.00371 & 0.00222 \\
\hline$\rho_{g}$ & AR government spending & 0.00116 & 0.00055 \\
\hline$\rho_{\mu^{x}}$ & AR non-stationary neutral productivity & 0.15107 & 0.02009 \\
\hline$\rho_{\mu}$ & AR wage markup & 0.00045 & 0.00011 \\
\hline$\rho_{\zeta}$ & AR preference & 0.00685 & 0.00491 \\
\hline$\rho_{z^{I}}$ & AR stationary investment-specific productivity & 0.02235 & 0.00100 \\
\hline$\sigma_{z}^{0}$ & std. stationary neutral productivity 0 & 0.03879 & 0.00488 \\
\hline$\sigma_{z}^{4}$ & std. stationary neutral productivity 4 & 2.09192 & 0.15462 \\
\hline$\sigma_{z}^{\tilde{8}}$ & std. stationary neutral productivity 8 & 1.51431 & 0.14918 \\
\hline$\sigma_{\mu}^{0} \mu^{a}$ & std. non-stationary investment-specific productivity 0 & 0.03482 & 0.00177 \\
\hline$\sigma_{\mu^{a}}^{4}$ & std. non-stationary investment-specific productivity 4 & 0.04562 & 0.00156 \\
\hline$\sigma_{\mu^{a}}^{8}$ & std. non-stationary investment-specific productivity 8 & 0.04740 & 0.00167 \\
\hline$\sigma_{g}^{0}$ & std. government spending 0 & 0.61389 & 0.02131 \\
\hline$\sigma_{g}^{4}$ & std. government spending 4 & 1.25121 & 0.11185 \\
\hline$\sigma_{g}^{8}$ & std. government spending 8 & 3.22258 & 0.27854 \\
\hline$\sigma_{\mu^{x}}^{0}$ & std. non-stationary neutral productivity 0 & 0.09638 & 0.02098 \\
\hline$\sigma_{\mu^{x}}^{\mu}$ & std. non-stationary neutral productivity 4 & 1.43272 & 0.08717 \\
\hline$\sigma_{\mu^{x}}^{8}$ & std. non-stationary neutral productivity 8 & 0.75869 & 0.07645 \\
\hline$\sigma_{\mu}^{0}$ & std. wage markup 0 & 6.52819 & 0.07706 \\
\hline$\sigma_{\mu}^{4}$ & std. wage markup 4 & 4.78828 & 0.46297 \\
\hline$\sigma_{\mu}^{8}$ & std. wage markup 8 & 6.02596 & 0.59652 \\
\hline$\sigma_{\zeta}^{0}$ & std. preference 0 & 59.14528 & 0.98231 \\
\hline$\sigma_{\zeta}^{4}$ & std. preference 4 & 99.49705 & 9.82559 \\
\hline$\sigma_{\zeta}^{8}$ & std. preference 8 & 33.00313 & 3.02169 \\
\hline$\sigma_{z^{I}}^{0}$ & std. stationary investment-specific productivity 0 & 70.24558 & 5.52009 \\
\hline$\sigma_{z}^{i}$ & std. stationary investment-specific productivity 4 & 104.96769 & 4.48185 \\
\hline$\sigma_{z^{I}}^{8}$ & std. stationary investment-specific productivity 8 & 44.03072 & 3.50932 \\
\hline
\end{tabular}

Note: $\boldsymbol{y}$ includes all observables, $\overline{\boldsymbol{y}}=\boldsymbol{y} \backslash\left(v^{f}, r\right)$. The bounds are computed for the MLE values in Table A.1 with $T=207$.

TABle A.2. CRLBs 


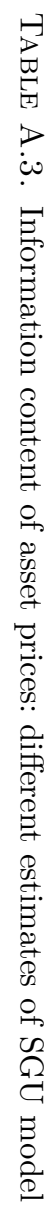

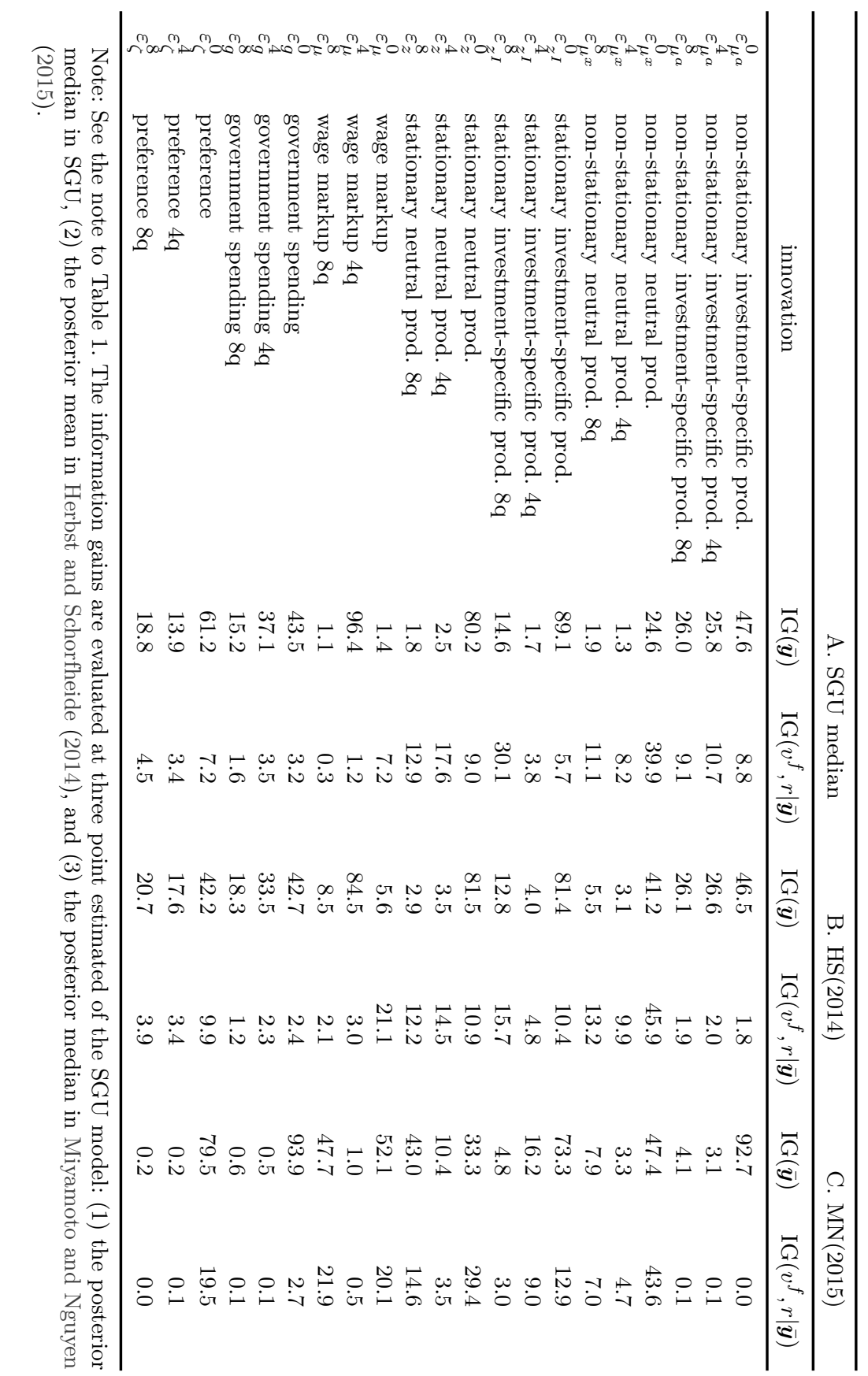




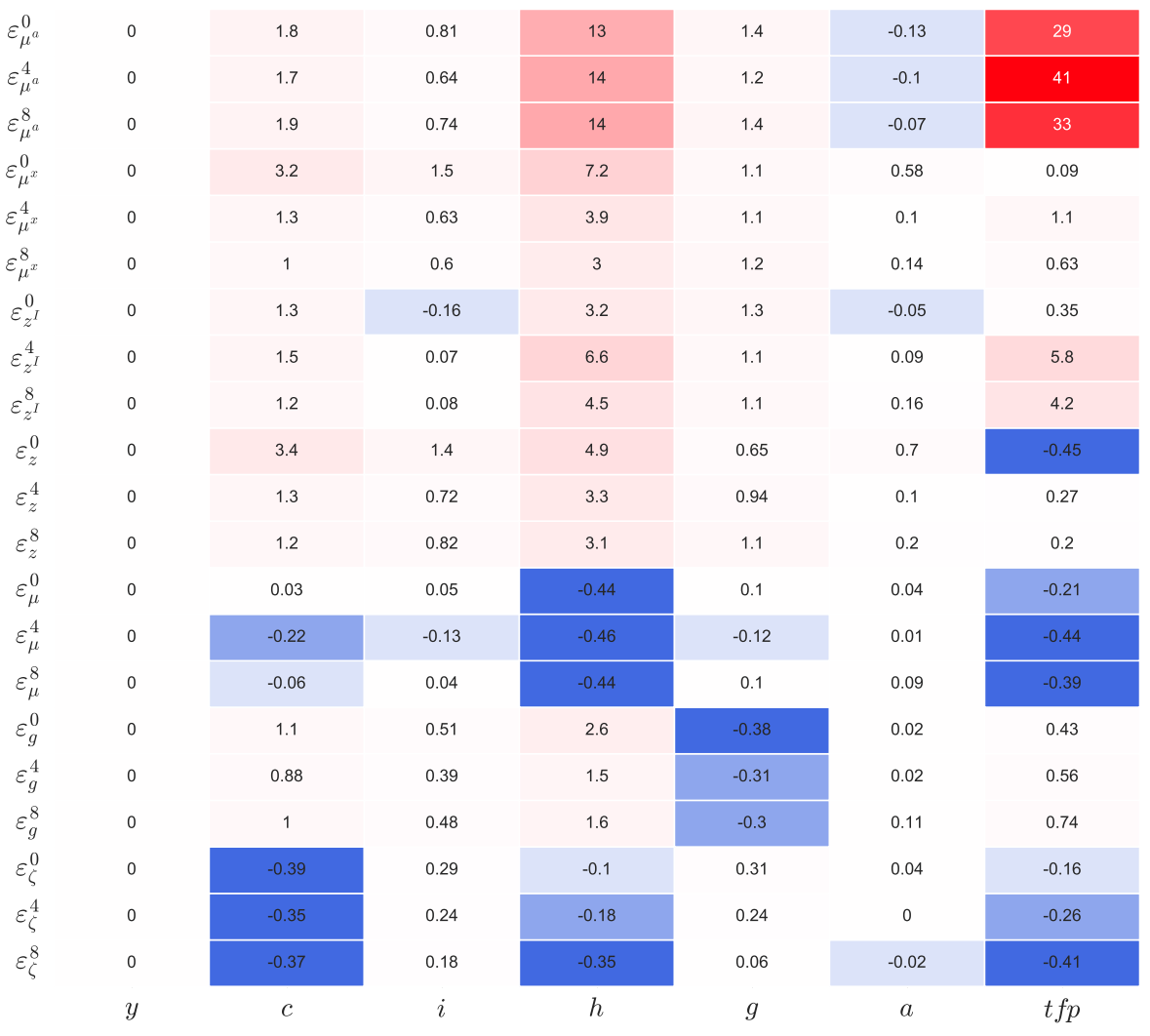

Figure A.1: Conditional pairwise complementarity between $v^{f}$ and macro variables at MLE in Schmitt-Grohé and Uribe (2012) 


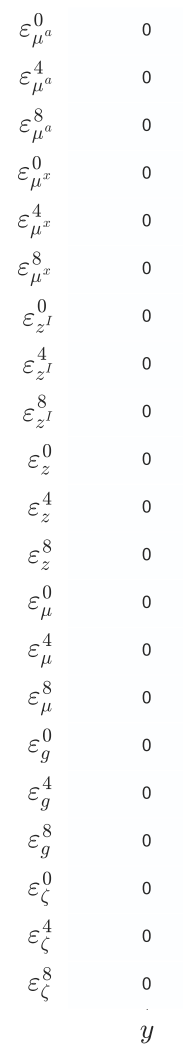

\begin{tabular}{|c|c|c|c|}
\hline 0.55 & 0.28 & 0.79 & 0.41 \\
\hline 0.93 & 0.49 & 3.2 & 0.42 \\
\hline 0.78 & 0.41 & 2.2 & 0.42 \\
\hline 0.3 & 0.13 & 1.6 & 0.27 \\
\hline 0.38 & 0.19 & 2.5 & 0.28 \\
\hline 0.33 & 0.17 & 2 & 0.26 \\
\hline 0.69 & -0.02 & 2.2 & 0.43 \\
\hline 0.66 & -0.03 & 2.9 & 0.3 \\
\hline 0.53 & -0.07 & 1.9 & 0.29 \\
\hline 0.37 & 0.18 & 1.1 & 0.15 \\
\hline 0.45 & 0.2 & 3.3 & 0.35 \\
\hline 0.43 & 0.19 & 2.9 & 0.34 \\
\hline 0.8 & 0.33 & 2.1 & 0.49 \\
\hline-0.3 & -0.24 & -0.46 & -0.22 \\
\hline-0.29 & -0.23 & -0.46 & -0.21 \\
\hline 0.42 & 0.19 & 3 & 0.05 \\
\hline 0.28 & 0.17 & 1.3 & -0.25 \\
\hline 0.17 & 0.12 & 0.8 & -0.25 \\
\hline 0.3 & 0.15 & 1.5 & 0.35 \\
\hline-0.29 & -0.11 & -0.26 & 0.04 \\
\hline-0.29 & -0.1 & -0.27 & 0.02 \\
\hline$c$ & $i$ & $h$ & $g$ \\
\hline
\end{tabular}

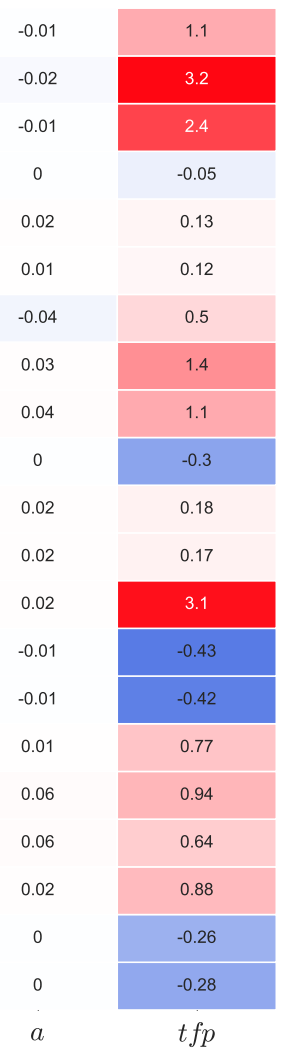

Figure A.2: Conditional pairwise complementarity between $r$ and macro variables at MLE in Schmitt-Grohé and Uribe (2012) 


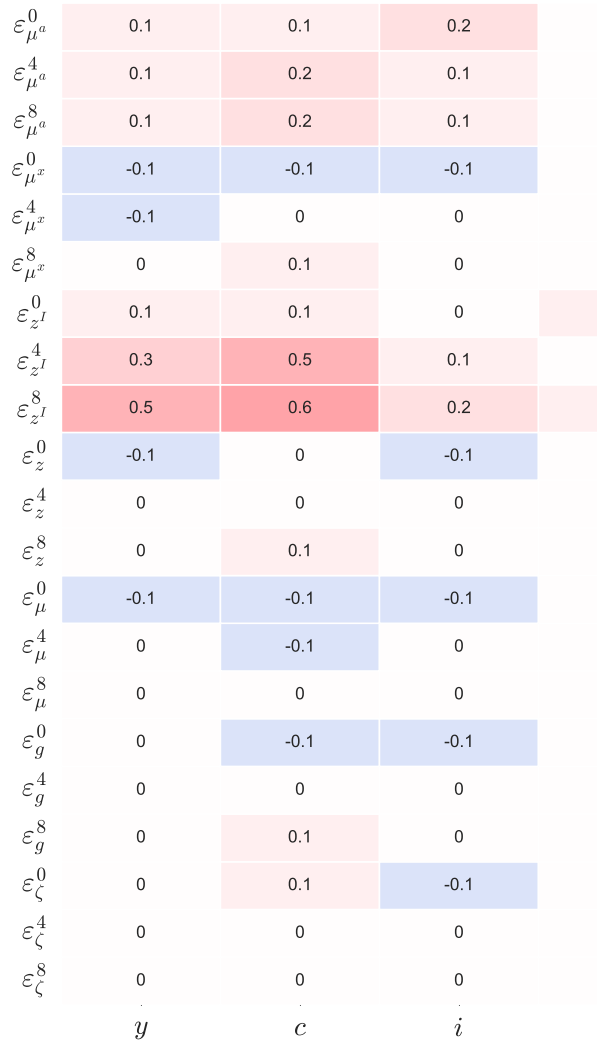

\begin{tabular}{|c|}
\hline-0.1 \\
\hline 0 \\
\hline 0 \\
\hline-0.1 \\
\hline-0.1 \\
\hline-0.1 \\
\hline 0.1 \\
\hline 0 \\
\hline 0 \\
0 \\
\hline 0 \\
0 \\
\hline 0 \\
0 \\
\hline 0 \\
0 \\
0 \\
0 \\
0 \\
\hline 0 \\
\hline
\end{tabular}

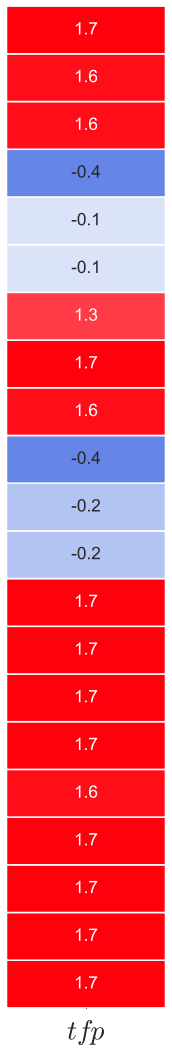

Figure A.3: Unconditional pairwise complementarity between $v^{f}$ and macro variables at MLE in Schmitt-Grohé and Uribe (2012) 


\begin{tabular}{|c|c|c|c|c|c|c|c|}
\hline$\varepsilon_{\mu^{a}}^{0}$ & -0.05 & 0.06 & -0.01 & 0.26 & -0.15 & 0 & 0.74 \\
\hline$\varepsilon_{\mu^{a}}^{4}$ & -0.1 & 0.04 & -0.02 & 0.67 & -0.06 & 0 & 0.23 \\
\hline$\varepsilon_{\mu^{a}}^{8}$ & -0.1 & 0.06 & -0.02 & 0.62 & -0.05 & 0 & 0.22 \\
\hline$\varepsilon_{\mu^{x}}^{0}$ & -0.12 & -0.08 & -0.09 & 0.25 & -0.09 & 0.01 & -0.03 \\
\hline$\varepsilon_{\mu^{x}}^{4}$ & 0.06 & 0.05 & 0.04 & 0.72 & 0.01 & 0 & -0.03 \\
\hline$\varepsilon_{\mu^{x}}^{8}$ & 0.08 & 0.07 & 0.05 & 0.71 & 0.01 & 0 & 0 \\
\hline$\varepsilon_{z^{I}}^{0}$ & 0.06 & 0.28 & 0 & 0.42 & 0.04 & 0 & 0.43 \\
\hline$\varepsilon_{z^{I}}^{4}$ & -0.1 & 0.15 & -0.06 & 0.51 & 0.03 & 0 & 0.22 \\
\hline$\varepsilon_{z^{I}}^{8}$ & -0.1 & 0.23 & -0.07 & 0.44 & 0.03 & 0 & 0.36 \\
\hline$\varepsilon_{z}^{0}$ & -0.13 & -0.07 & -0.09 & 0.29 & 0.09 & 0.01 & -0.09 \\
\hline$\varepsilon_{z}^{4}$ & 0.05 & 0.03 & 0.03 & 0.8 & 0.02 & 0 & -0.07 \\
\hline$\varepsilon_{z}^{8}$ & 0.06 & 0.04 & 0.03 & 0.79 & 0.02 & 0 & -0.06 \\
\hline$\varepsilon_{\mu}^{0}$ & -0.18 & -0.13 & -0.1 & 0.17 & 0.05 & 0.01 & 0.62 \\
\hline$\varepsilon_{\mu}^{4}$ & 0.04 & 0.01 & 0.01 & -0.29 & 0.02 & 0 & 0.05 \\
\hline$\varepsilon_{\mu}^{8}$ & 0.06 & 0.03 & 0.03 & -0.28 & 0.02 & 0 & 0.06 \\
\hline$\varepsilon_{g}^{0}$ & 0.02 & -0.12 & -0.09 & 0.35 & 0.02 & 0.01 & 0.6 \\
\hline$\varepsilon_{g}^{4}$ & -0.1 & 0.03 & 0.03 & 0.86 & -0.03 & 0 & 0.06 \\
\hline$\varepsilon_{g}^{8}$ & -0.11 & 0.05 & 0.03 & 0.85 & -0.03 & 0 & 0.06 \\
\hline$\varepsilon_{\zeta}^{0}$ & 0.02 & 0.03 & -0.06 & 0.28 & 0.05 & 0.01 & 0.6 \\
\hline$\varepsilon_{\zeta}^{4}$ & -0.1 & -0.04 & 0.04 & 0.82 & 0.02 & 0 & 0.07 \\
\hline \multirow[t]{2}{*}{$\varepsilon_{\zeta}^{8}$} & -0.1 & -0.04 & 0.05 & 0.83 & 0.02 & 0 & 0.08 \\
\hline & $y$ & $c$ & $i$ & $h$ & $g$ & $a$ & $t f p$ \\
\hline
\end{tabular}

Figure A.4: Unconditional pairwise complementarity between $r$ and macro variables at MLE in Schmitt-Grohé and Uribe (2012) 


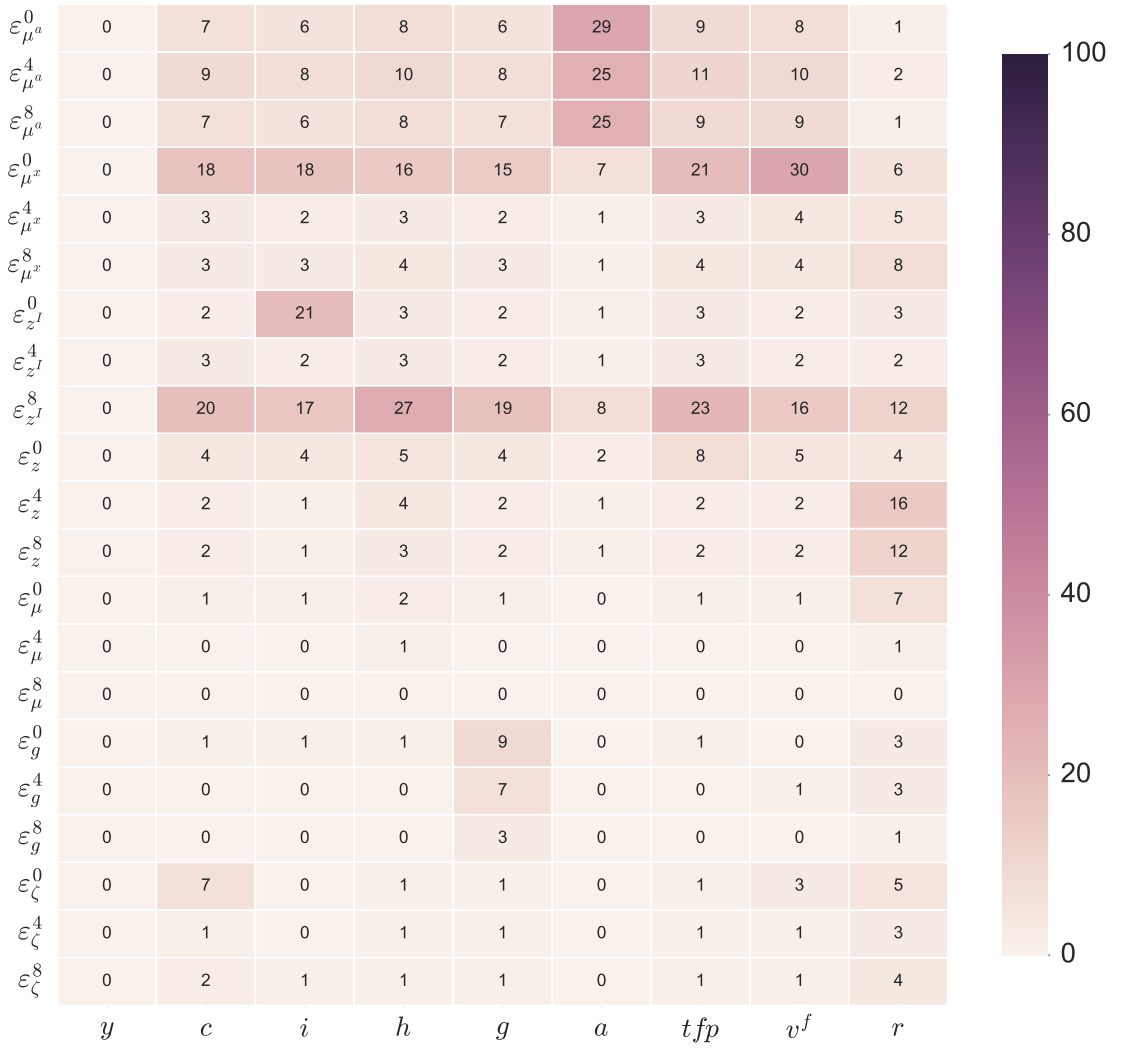

Figure A.5: Conditional information gains at the posterior median in Schmitt-Grohé and Uribe (2012) 


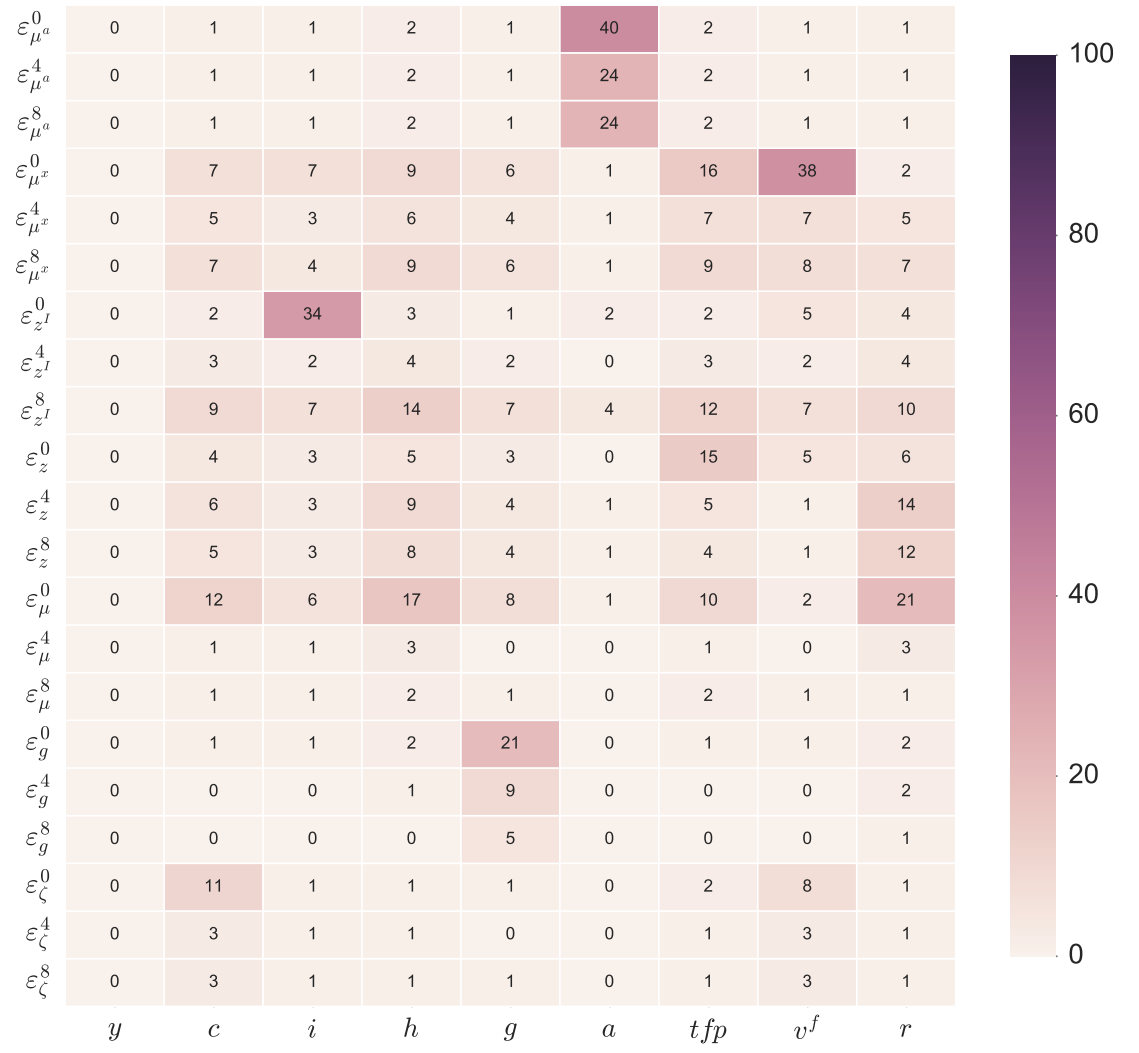

Figure A.6: Conditional information gains at the posterior mean in Herbst and Schorfheide (2014) 


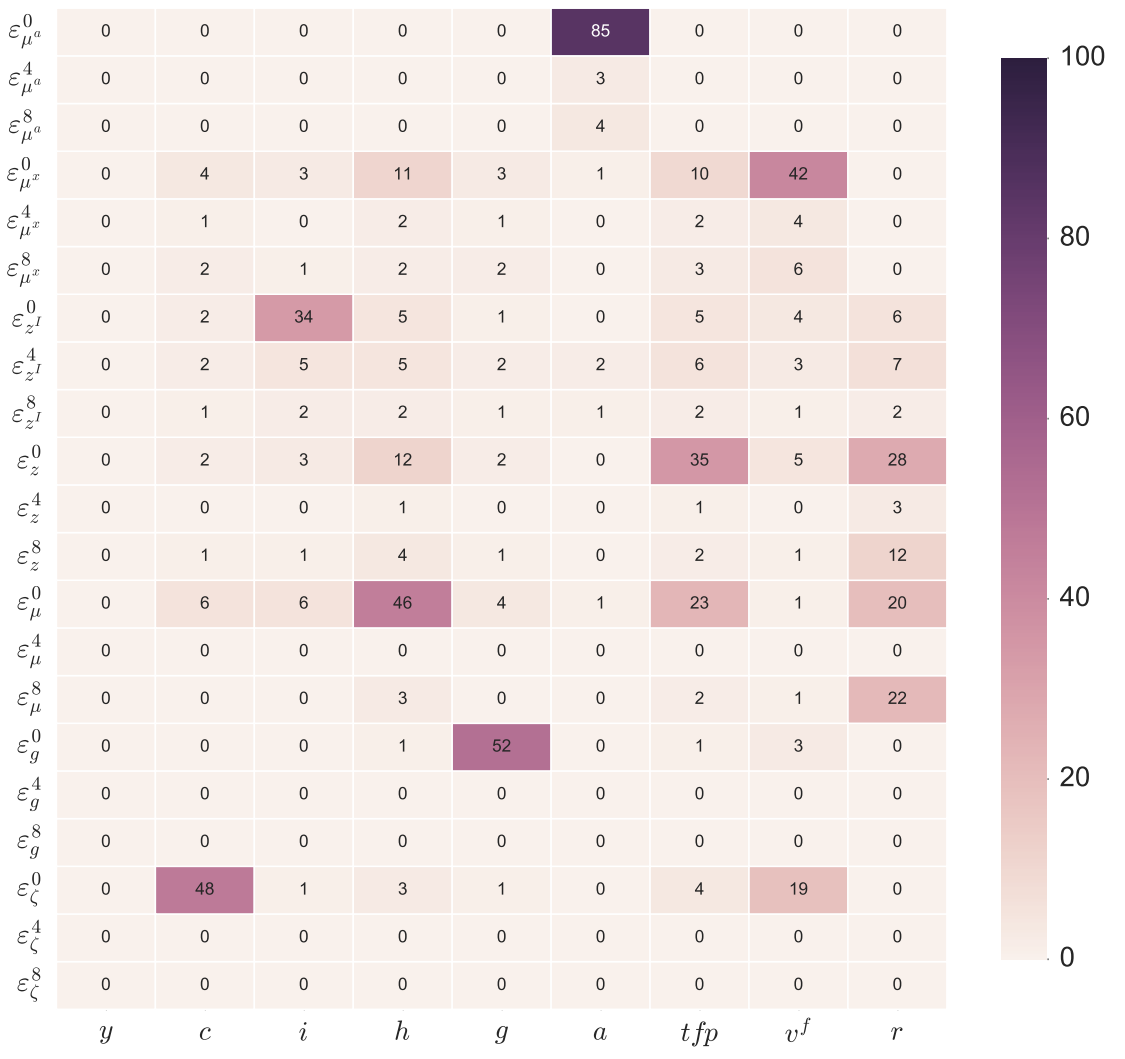

Figure A.7: Conditional information gains at the posterior median in Miyamoto and Nguyen (2015) 


\section{A.2. Avdjiev (2016) model}

\begin{tabular}{llc}
\hline & \multicolumn{1}{c}{ parameter } & value \\
\hline$\gamma$ & inverse intertemporal elasticity of substitution & 0.90 \\
$\chi$ & Frisch elasticity of labor supply & 2.90 \\
$\theta_{l}$ & habit in leisure, & 0.12 \\
$\theta_{c}$ & habit in consumption, & 0.22 \\
$\delta_{2}$ & capacity utilization cost & 3.91 \\
$\eta$ & investment adjustment cost & 0.29 \\
$\rho_{x}^{l}$ & AR non-stationary neutral productivity & 0.01 \\
$\rho_{a}^{l}$ & AR non-stationary investment-specific productivity & 0.32 \\
$\rho_{z}^{l}$ & AR stationary neutral productivity & 0.57 \\
$\rho_{\omega}$ & AR stationary investment-specific productivity & 0.91 \\
$\sigma_{x, u}$ & std. non-stationary neutral productivity & 1.05 \\
$\sigma_{x, L R}$ & std. non-stationary neutral productivity LR news & 0.01 \\
$\sigma_{a, u}$ & std. non-stationary investment-specific productivity & 0.95 \\
$\sigma_{a, L R}$ & std. non-stationary investment-specific productivity LR news & 0.13 \\
$\sigma_{z, u}$ & std. stationary neutral productivity & 0.93 \\
$\sigma_{z, L R}$ & std. stationary neutral productivity LR news & 0.92 \\
$\sigma_{\omega, u}$ & std. stationary investment-specific productivity & 9.97 \\
$\sigma_{\omega, L R}$ & std. stationary investment-specific productivity LR news & 0.07 \\
\hline
\end{tabular}

Note: The values are the posterior median estimates reported in Table D.2 of Avdjiev (2016).

TABle A.4. Parameter values, Avdjiev (2016) model 


\begin{tabular}{llrr}
\hline & \multicolumn{1}{c}{ parameter } & \multicolumn{1}{c}{} & \multicolumn{1}{c}{$\boldsymbol{y}$} \\
\hline$\gamma$ & inverse intertemporal elasticity of substitution & 0.00024 & 0.00020 \\
$\chi$ & Frisch elasticity of labor supply & 443.84281 & 6.00170 \\
$\theta_{l}$ & habit in leisure, & 0.00995 & 0.00601 \\
$\theta_{c}$ & habit in consumption, & 0.00006 & 0.00004 \\
$\delta_{2}$ & capacity utilization cost & 1057.97045 & 128.57305 \\
$\eta$ & investment adjustment cost & 0.00609 & 0.00071 \\
$\rho_{x}^{l}$ & AR non-stationary neutral productivity & 0.00439 & 0.00066 \\
$\rho_{a}$ & AR non-stationary investment-specific productivity & 0.00461 & 0.00371 \\
$\rho_{z}^{l}$ & AR stationary neutral productivity & 0.01160 & 0.00117 \\
$\rho_{\omega}$ & AR stationary investment-specific productivity & 0.00201 & 0.00097 \\
$\sigma_{x, u}$ & std. non-stationary neutral productivity & 0.00548 & 0.00370 \\
$\sigma_{x, L R}$ & std. non-stationary neutral productivity LR news & 0.00003 & 0.00002 \\
$\sigma_{a, u}$ & std. non-stationary investment-specific productivity & 0.00206 & 0.00196 \\
$\sigma_{a, L R}$ & std. non-stationary investment-specific productivity LR news & 0.00086 & 0.00027 \\
$\sigma_{z, u}$ & std. stationary neutral productivity & 0.00391 & 0.00214 \\
$\sigma_{z, L R}$ & std. stationary neutral productivity LR news & 0.02206 & 0.00790 \\
$\sigma_{\omega, u}$ & std. stationary investment-specific productivity & 8.20461 & 0.79912 \\
$\sigma_{\omega, L R}$ & std. stationary investment-specific productivity LR news & 965.05866 & 132.27654 \\
\hline
\end{tabular}

Note: $\boldsymbol{y}$ includes all observables, $\overline{\boldsymbol{y}}=\boldsymbol{y} \backslash\left(v^{f}, r\right)$ The CRLBs are computed for the parameter values in Table A. 4 using $T=236$.

TABle A.5. Cramér-Rao lower bounds, Avdjiev (2016) model. 


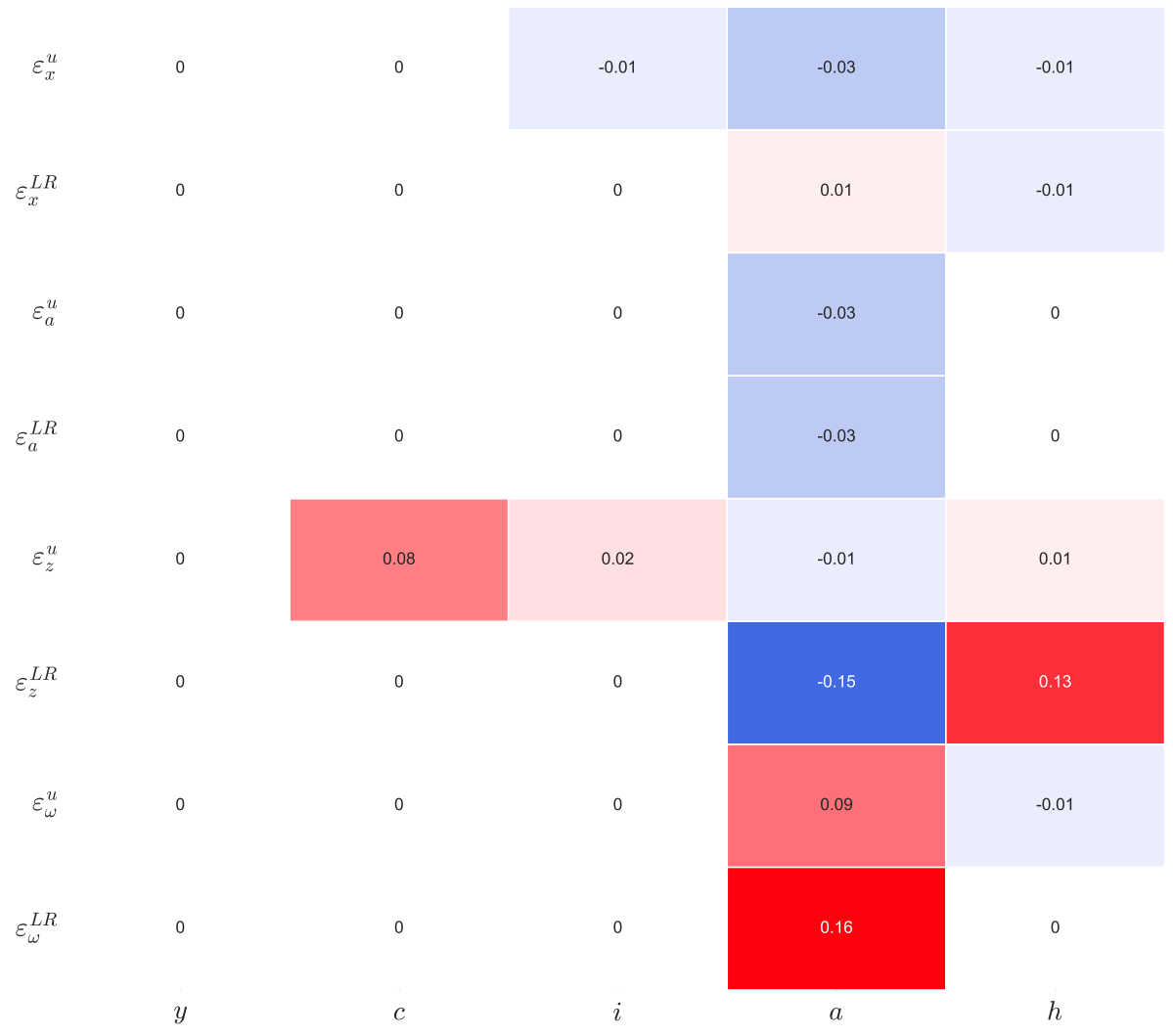

Figure A.8: Conditional pairwise complementarity between $v^{f}$ and macro variables Avdjiev (2016) 


\begin{tabular}{|c|c|c|c|c|c|}
\hline$\varepsilon_{x}^{u}$ & 0 & 0 & 0 & -0.02 & -0.03 \\
\hline$\varepsilon_{x}^{L R}$ & 0 & 0 & 0 & 0.65 & 0.16 \\
\hline$\varepsilon_{a}^{u}$ & 0 & 0 & 0 & -0.02 & -0.01 \\
\hline$\varepsilon_{a}^{L R}$ & 0 & 0 & 0 & -0.07 & -0.01 \\
\hline$\varepsilon_{z}^{u}$ & 0 & -0.06 & 0 & -0.12 & -0.19 \\
\hline$\varepsilon_{z}^{L R}$ & 0 & 0 & 0 & -0.05 & -0.02 \\
\hline$\varepsilon_{\omega}^{u}$ & 0 & 0.01 & 0 & -0.02 & 0.03 \\
\hline$\varepsilon_{\omega}^{L R}$ & 0 & 0 & 0 & -0.08 & -0.03 \\
\hline & $y$ & $c$ & $i$ & $a$ & $h$ \\
\hline
\end{tabular}

Figure A.9: Conditional pairwise complementarity between $r$ and macro variables Avdjiev (2016) 


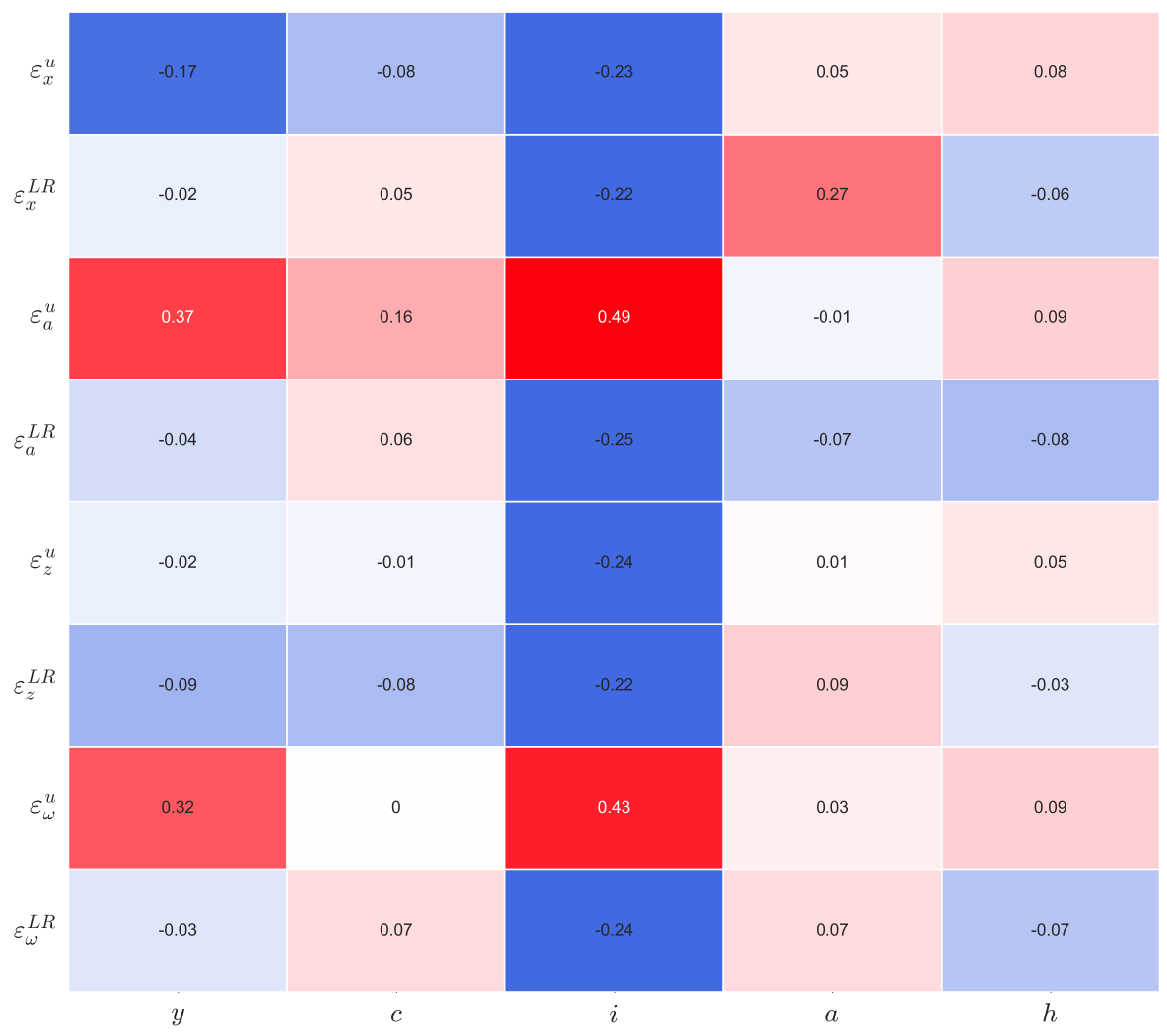

Figure A.10: Unconditional pairwise complementarity between $v^{f}$ and macro variables

Avdjiev (2016) 


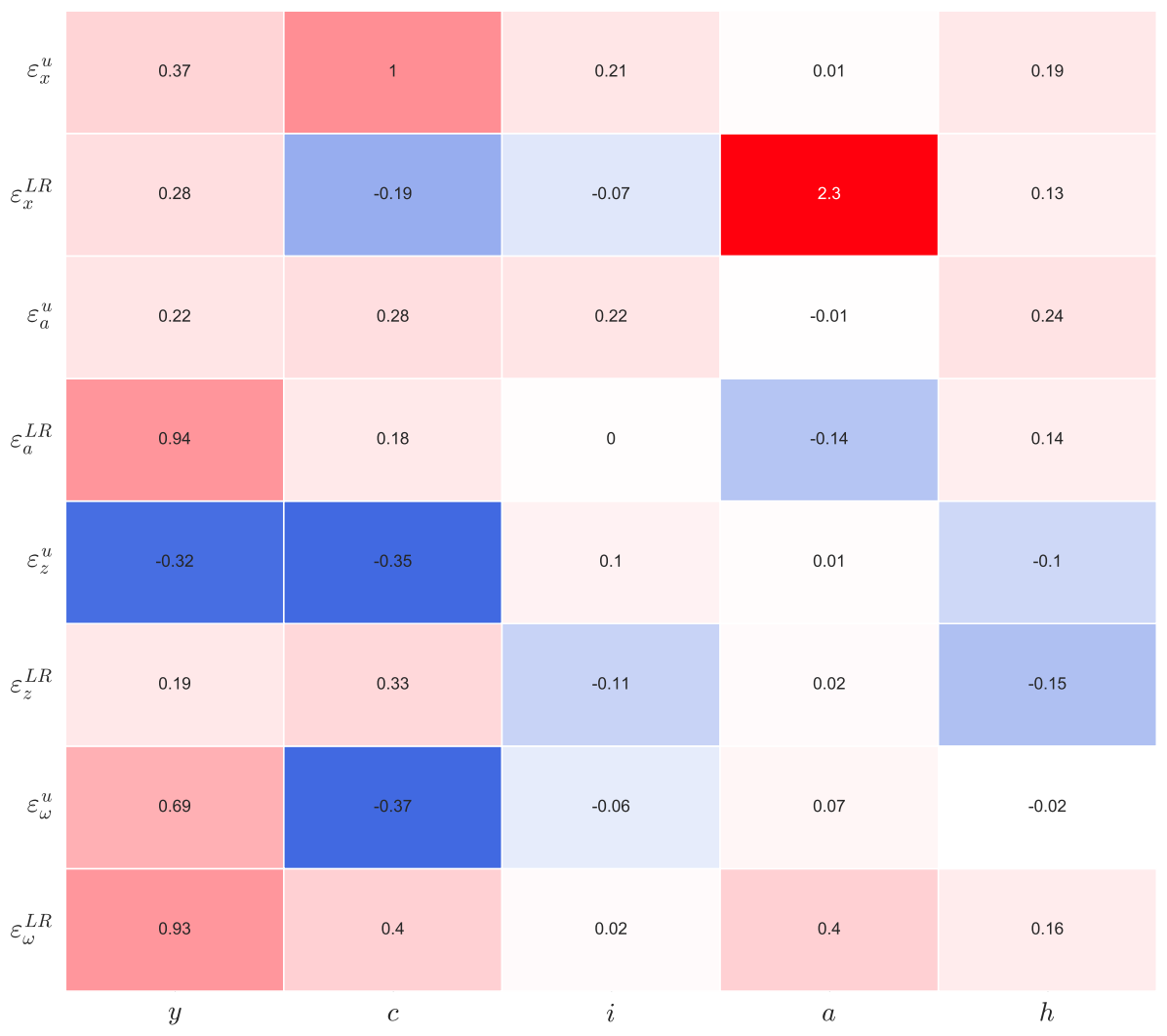

Figure A.11: Unconditional pairwise complementarity between $r$ and macro variables Avdjiev (2016) 


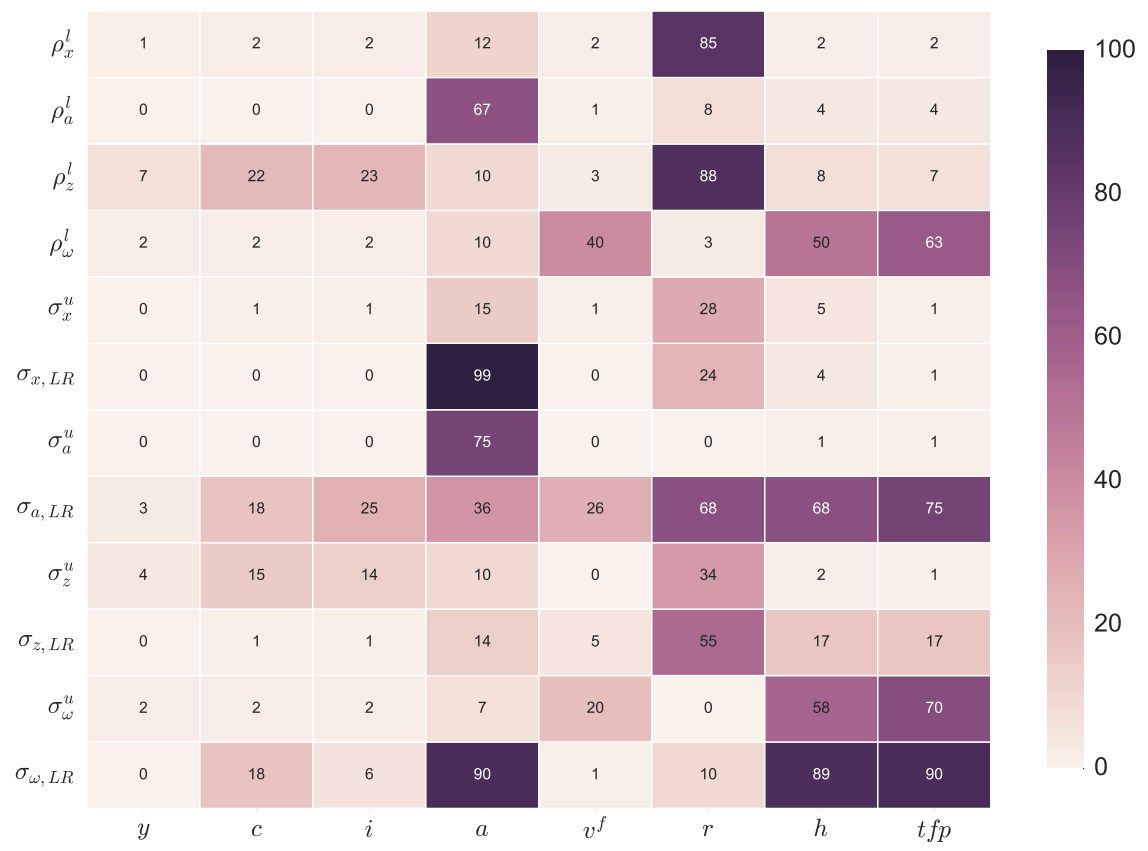

Figure A.12: Efficiency gains in the model of Avdjiev (2016) when $t f p$ is observed. 


\section{Working Papers}

\section{6}

1|16 A mixed frequency approach to forecast private consumption with ATM/POS data Cláudia Duarte | Paulo M. M. Rodrigues | António Rua

2|16 Monetary developments and expansionary fiscal consolidations: evidence from the EMU António Afonso | Luís Martins

3|16 Output and unemployment, Portugal, 2008-2012

José R. Maria

4|16 Productivity and organization in portuguese firms

Lorenzo Caliendo | Luca David Opromolla | Giordano Mion | Esteban Rossi-Hansberg

5|16 Residual-augmented IVX predictive regression

Matei Demetrescu | Paulo M. M. Rodrigues

6|16 Understanding the public sector pay gap Maria M. Campos | Evangelia Papapetrou | Domenico Depalo Javier J. Pérez | Roberto Ramos

7|16 Sorry, we're closed: Ioan conditions when bank branches close and firms transfer to another bank

Diana Bonfim | Gil Nogueira | Steven Ongena

8|16 The effect of quantitative easing on lending conditions

Laura Blattner | Luísa Farinha | Gil Nogueira

9|16 Market integration and the persistence of electricity prices

João Pedro Pereira | Vasco Pesquita | Paulo M. M. Rodrigues | António Rua
10|16 EAGLE-FLI | A macroeconomic model of banking and financial interdependence in the euro area

N. Bokan | A. Gerali | S. Gomes | P. Jacquinot | M. Pisani

11|16 Temporary contracts' transitions: the role of training and institutions

Sara Serra

12|16 A wavelet-based multivariate multiscale approach for forecasting

António Rua

13|16 Forecasting banking crises with dynamic panel probit models

António Antunes | Diana Bonfim | Nuno Monteiro | Paulo M. M. Rodrigues

14|16 A tale of two sectors: why is misallocation higher in services than in manufacturing? Daniel A. Dias | Carlos Robalo Marques | Christine Richmond

15|16 The unsecured interbank money market: a description of the Portuguese case Sofia Saldanha

16|16 Leverage and risk weighted capital requirements

Leonardo Gambacorta | Sudipto Karmakar

17|16 Surviving the perfect storm: the role of the lender of last resort

Nuno Alves | Diana Bonfim | Carla Soares

18|16 Public debt expansions and the dynamics of the household borrowing constraint

António Antunes | Valerio Ercolani 


\section{7}

$1 \mid 17$ The diffusion of knowledge via managers mobility

Giordano Mion | Luca David Opromolla | Alessandro Sforza

2|17 Upward nominal wage rigidity

Paulo Guimarães | Fernando Martins | Pedro Portugal

3|17 Zooming the ins and outs of the U.S. unemployment

Pedro Portugal | António Rua

4|17 Labor market imperfections and the firm's wage setting policy

Sónia Félix | Pedro Portugal

5|17 International banking and cross-border effects of regulation: lessons from Portugal

Diana Bonfim | Sónia Costa

6|17 Disentangling the channels from birthdate to educational attainment

Luís Martins | Manuel Coutinho Pereira

7|17 Who's who in global value chains? A weighted network approach

João Amador | Sónia Cabral | Rossana Mastrandrea | Franco Ruzzenenti

8|17 Lending relationships and the real economy: evidence in the context of the euro area sovereign debt crisis Luciana Barbosa
9|17 Impact of uncertainty measures on the Portuguese economy

Cristina Manteu | Sara Serra

10|17 Modelling currency demand in a small open economy within a monetary union

António Rua

11|17 Boom, slump, sudden stops, recovery, and policy options. Portugal and the Euro Olivier Blanchard | Pedro Portugal

12|17 Inefficiency distribution of the European Banking System

João Oliveira

13|17 Banks' liquidity management and systemic risk

Luca G. Deidda | Ettore Panetti

14|17 Entrepreneurial risk and diversification through trade

Federico Esposito

15|17 The portuguese post-2008 period: a narrative from an estimated DSGE model Paulo Júlio | José R. Maria

16|17 A theory of government bailouts in a heterogeneous banking system Filomena Garcia | Ettore Panetti

17|17 Goods and factor market integration: a quantitative assessment of the EU enlargement FLorenzo Caliendo | Luca David Opromolla | Fernando Parro | Alessandro Sforza 


\section{8}

1|18 Calibration and the estimation of macroeconomic models

Nikolay Iskrev

2|18 Are asset price data informative about news shocks? A DSGE perspective

Nikolay Iskrev 
www.bportugal.pt 